\title{
İnceltilmiş Uçlu Önüretimli Aşık Kirişlerinin Yük Taşıma Kapasitelerinin Deneysel ve Numerik Olarak İrdelenmesi ve Çözüm Önerileri
}

\author{
Ceyhun AKSOYLU ${ }^{1}$ \\ Yasin Onuralp ÖZKILIÇ² \\ Şakir YAZMAN ${ }^{3}$ \\ Lokman GEMi ${ }^{4}$ \\ Musa Hakan ARSLAN 5
}

\section{$\ddot{O Z Z}$}

Türkiye'de inşaat sektörü 1960'lı yılların sonu itibari ile beton prefabrikasyon ile tanışmıştır. Prefabrike olarak üretilen yapılar seri üretimlerinin ve montajlarının hızlı olmasından dolayı özellikle sanayi yapılarında daha fazla tercih edilmişlerdir. Bu yapı türünün en büyük dezavantajı özellikle mafsallı birleşim bölgelerinde oluşan hasarlardır. Çatı kirişleri ile aşık kirişlerinin birleştiği bölgelerde de bağlantı genellikle mafsallı olarak gerçekleştirilir. Bundan dolayı mesnet bölgelerinde teorik olarak moment oluşmamakta ve bu tip kirişlerin kesit tesirleri basit mesnetli kirişlerde olduğu gibi hesaplanmaktadır. Ancak aşık inceltilmiş uç bölgelerinde yoğunlaşan kesme kuvveti, kesme gerilmelerinin artmasına neden olduğundan bu bölgenin detaylandırılması için bir takım özel tasarım kuralları ilgili standartlarda yer almıştır. Bu birleşim bölgelerinde özellikle etkili ve uzun süreli kar yağışlarından sonra çatıda biriken yoğun kar neticesinde hasarlar gözlemlenmektedir. Bu hasarlar nispeten daha eski prefabrike yapı stokunda bulunanlar başta olmak üzere inceltilmiş uçlu aşık kirişleri için önemli bir risk oluşturmaktadır. Bu çalışmada, şimdiye kadar kapsamlı olarak araştırılmamış olan inceltilmiş uçlu aşıkların düşey yük etkisi altında davranışları, aşıkların değişen mekanik parametrelerine göre deneysel ve numerik olarak incelenmiştir. İlk olarak yürürlükteki standartlara uygun olan ve olmayan iki adet aşık kirişinin deneyleri

\footnotetext{
Not: Bu yazı

- Yayın Kurulu'na 29 Aralık 2019 günü ulaşmıştır. 28 Eylül 2020 günü yayımlanmak üzere kabul edilmiştir.

- 31 Temmuz 2021 gününe kadar tartışmaya açıktır.

- https://doi.org/10.18400/tekderg.667066

1 Konya Teknik Üniversitesi, İnşaat Mühendisliği Bölümü, Konya - caksoylu@ktun.edu.tr https://orcid.org/0000-0002-1574-4251

2 Necmettin Erbakan Üniversitesi, İnşaat Mühendisliği Bölümü, Konya - yozkilic@erbakan.edu.tr https://orcid.org/0000-0001-9354-4784

3 Selçuk Üniversitesi, Ilgın Meslek Yüksek Okulu, Konya - syazman@selcuk.edu.tr https://orcid.org/0000-0002-4064-0024

4 Necmettin Erbakan Üniversitesi, Meram Meslek Yüksekokulu, Konya - lgemi@erbakan.edu.tr https://orcid.org/0000-0002-9895-6574

5 Konya Teknik Üniversitesi, İnşaat Mühendisliği Bölümü, Konya - mharslan@ktun.edu.tr https://orcid.org/0000-0002-5410-9218
} 
gerçekleştirilmiştir. Ardından yine standarda uygun bir adet aşık kiriş inceltilmiş uç hasarının önlenlenmesi amacıyla CFRP ile güçlendirilerek test edilmiştir. Daha sonra ABAQUS programıyla modellenen aşıklardan elde edilen sonuçlar ile deneysel çalışma sonuçları doğrulanmıştır. Tüm deneysel sonuçlarla numerik modelleme sonuçlarının oldukça yakın olduğu görülmüştür. Numerik model numunelerinde gözlenen hasarlar ile deneylerde oluşan hasarların benzer olması yeni parametrik çalışmalarda numerik modellerin kullanılabileceğini göstermiş̧tir. Doğrulamanın ardından aşıkların mekanik özellikleri ile güçlendirme alternatiflerine bağlı bir dizi parametrik çalışma numerik olarak gerçekleştirilmiştir. Parametrik çalışmada; özellikle mevcut aşıklarda beton basınç dayanımı, donatı çekme dayanımı ve aşı kirişlerin üretiminde kullanılan öngerme seviyesinin tasarlanandan farklı olabileceği düşüncesiyle bir parametre olarak değerlendirilmiştir. Ayrıca karbon elyaf takviyeli polimer (CFRP) kumaş ile güçlendirilen ve yönetmeliğe göre tasarlanmayan aşıkların davranı̧̧ı da yine parametrik çalışma kısmında incelenmiştir. Parametrik çalışmanın sonuçlarına göre beton basınç dayanımı daha etkin olmakla beraber beton ve çelik dayanımının artışı ile kesme kapasitesinde önemli ölçüde artış sağlandığ görülmüş̧ür. Elde edilen sonuçlarda öngerme değeri artı̧ııın kapasiteye hatırı sayılır bir etki sağlamadığı görülmüştür. CFRP ile güçlendirilen numunelerde aşığın yük taşıma kapasitesinin \%50'ye arttı̆̆ ve hasarın inceltilmiş uç bölgesi dışına kaydığ (inceltilmemiş bölgeye) görülmüştür. Parametrik çalışma ile farklı ve uygulanabilir CFRP alternatifleri de modellenerek en iyi güçlendirme alternatifi önerilmiştir. Bununla beraber inceltilmiş uçlu aşıkların donatı tasarımına esas bazı öneriler getirilmiş̧ir.

Anahtar Kelimeler: ABAQUS, CFRP, inceltilmiş uç, aşık kiriş, prefabrik yapı.

\section{ABSTRACT \\ Experimental and Numerical Investigation of Load Bearing Capacity of Thinned End Precast Purlin Beams and Solution Proposals}

The construction sector in Turkey has met concrete prefabrication at the end of the 1960s. Prefabricated structures have been preferred more especially in industrial buildings due to their rapid production and fast erecting. The biggest disadvantage of these structures is the damages that occurred at especially the region of hinged connection. The connection of roof beams and purlin beams are generally assembled with a hinged connection. Therefore, a moment does not occur theoretically in the support areas and the cross-sectional effects of these beams are calculated as in simple support beams. However, since the shear force concentrated in the thinned end regions causes an increase in shear stresses, a number of special design rules are included in the relevant standards for the detailing of this region. Damages are observed in these connections as a result of snow accumulated on the roof especially after effective and prolonged snowfall. These damages pose a significant risk for thinned end beams, especially those in the relatively older prefabricated building stock. In this present study, the behavior of thinned end purlins under vertical loading, which have not been investigated extensively before, has been numerically and experimentally examined according to varying mechanical parameters. First, experiments of two purlin beam, which are in accordance with current standards and not, were carried out. Then another purlin beam in accordance with the standard, which was strengthened with carbon fiber reinforced polymer (CFRP) in order to prevent thinned end damage, was tested. Then, the results 
obtained from the purlins modeled with ABAQUS program were verified with the results of the experimental study. The results of numerical modeling were found to be very close to all experimental findings. The similarities between the damages observed in the experiments and numerical modeling showed that numerical models can be used in new parametric studies. After the verificifation, a number of parametric studies related to the mechanical properties of the purlins and strengthening alternatives were performed numerically. In the parametric study, concrete compressive strength, reinforcement tensile strength and the prestressing level used in the production of purlin beams, especially in existing purlin, was evaluated as a parameter with the idea that it may differ from the designed one. In addition, the behavior of purlins which are not in accordance with standards and strengthened with CFRP was also examined in the parametric study section. According to the results of the parametric study, it has been observed that a significant increase in shear capacity has been achieved with the increase of concrete and steel strength although the concrete compressive strength is more effective. The results showed that increasing the pretension value does not have a significant effect on the capacity. In addition, the shear capacity of purlin strengthened with CFRP has increased up to $50 \%$ and the damage has shifted to out of the thinned end region. With the aid of parametric study, different and feasible CFRP alternatives were also modeled and the best strengthening alternative was recommended. In addition, some suggestions for the design of the reinforcements for the thinned ended purlins were made.

Keywords: ABAQUS, CFRP, thinned end, purlin, prefabricated building.

\section{GíRiș}

Prefabrikasyon (Önüretim); kullanım amacına göre dayanım, görünüm ve zaman açısından ihtiyaçlara maksimum seviyede cevap verebilen bir yapım sistemi oluşturmak amacıyla fabrikada seri olarak üretilen ve yerinde montajı hızlı yapı türüdür [1]. Ülkemizde prefabrike yapıların ilk olarak kullanımı 1950'li yıllara dayanmaktadır [2]. Daha sonraki yıllarda sanayiye yönelik yatırımların artmasıyla beraber 1980'li yıllarda kullanımı ancak yaygınlaşabilmiştir. Üretilen prefabrike yapıların büyük bir kısmı ise sanayi yapılarından oluşmaktadır [3]. Bu tür yapılar genellikle temelden ankastre olup tek katlı, geniş açıklığa sahip, kolon, kiriş ve çatı elemanlarından oluşan çerçeve tipini temsil etmektedir (Şekil 1 ve Şekil 2).

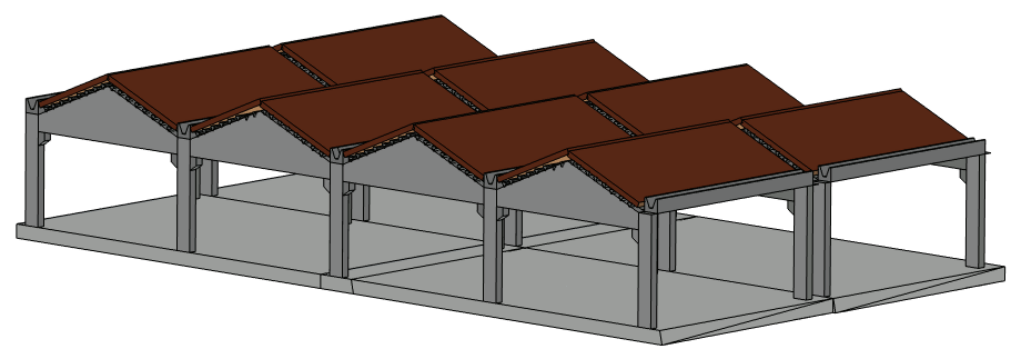

Şekil 1 - Tipik prefabrik sanayi yapısı örneği 


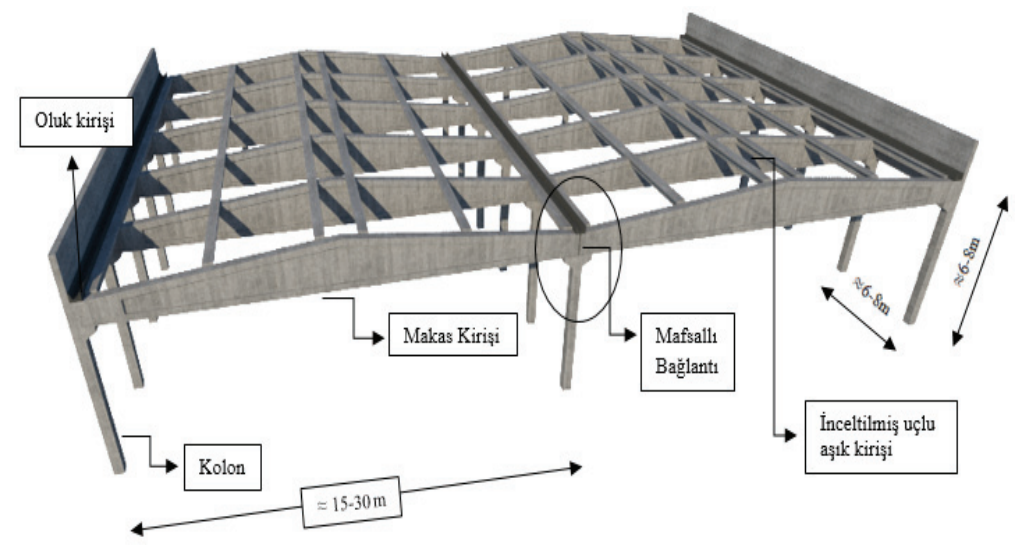

Şekil 2 - Mafsallı prefabrik yapının tipik görünümü

Prefabrike yapılarda bağlantı türleri, moment aktaran prefabrik panellerden veya mafsallı olabilmektedir. Özellikle çatı kirişi olarak kullanılan inceltilmiş uçlu aşık kirişlerinde mafsallı bağlantılar tercih edilmektedir (Şekil 2). Ancak bu durumda aşık kirişlerinin inceltilmiş uç kısımlarında düşey yükler altında (kar vb.) ani ve gevrek hasarların oluştuğu literatürdeki çok sayıda çalışmada belirtilmiştir [4-12]. Prefabrike yapılarda biriken kar yükünün zamanla inceltilmiş uçlu aşık elemanlarında oluşturduğu yükleme durumu Şekil 3'de gösterilmektedir.

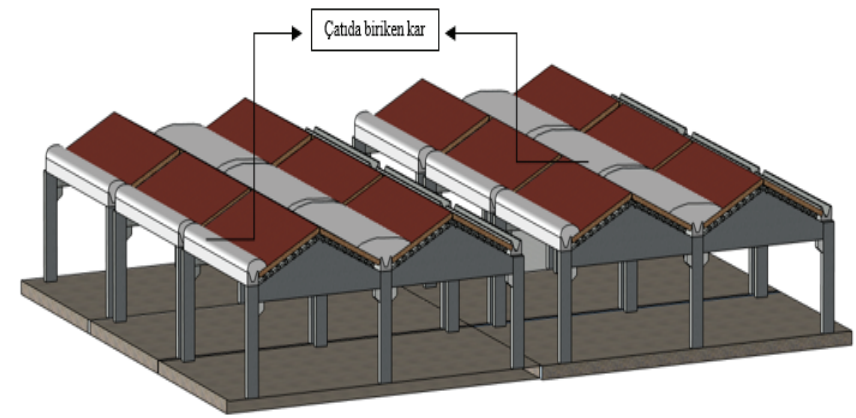

Şekil 3 - Prefabrike yapılarda zamanla kar yükünün birikmesi

İnceltilmiş uçlarda meydana gelen hasar ve hasarlara yönelik alınması gereken önlemleri içeren literatür de farklı analitik ve deneysel çalışmalar da mevcuttur [13-34]. İnceltilmiş uçlu aşık kirişlerinin tasarımına yönelik 1979 yılında Mattock ve Chan tarafından yapılan deneysel çalışmalar [5] 1999 yılında çıkarılan Amerikan prefabrik yapı yönetmeliğine [35] (PCI Design Handbook) altlık oluşturmuş ve inceltilmiş uç bölgelerinin tasarımı bu sayede iyileştirilmiştir. Bununla beraber ülkemizde inceltilmiş uçlu öngermeli aşık kirişlerin tasarımına yönelik şu anda yürürlükte olmayan ancak yerine alternatif getirilmediğinden kullanılan TS 9967 [36] ve TS 3233 [37] standartları mevcuttur. Prefabrik yapı üreticileri 
tarafından kullanılan bu standartlar, inceltilmiş uçlu aşık kirişlerin tasarımına ait denklemler ve donatı düzeni vermektedir. 2010 yılında yürürlükten kalkan TS 9967'nin yerine geçmesi için sektörde referans döküman olarak kullanılan Türkiye Prefabrik Birliği Teknik Komitesi'nin hazırladığı "Beton Prefabrikasyon El Kitabı (BPEK-2018) [38] en güncel kaynak olarak da kullanılmaktadır. Ayrıca deprem etkisi altında yapılacak hesaplar ve birleşim bölgesi detayları TBDY-2019'da [39] verilmiştir. Tasarımın ardından geniş açıklıklı çatılar için üretimi yapılan aşıkların inceltilmiş uç bölgelerinde zamanla biriken kar yükü risk ve hasar oluş̧urmaktadır. Bu hasarların nedeni ise kar yükünün TS 498'de belirtildiği üzere ilgili bölgeye göre karakteristik bir yük olarak dikkate alınmasıdır. Ancak bir bölgedeki zemin kar yükü ile çatı kar yükü arasında zamana bağlı olarak çok ciddi farklar olduğu bilinmektedir. TS-EN- 1991 1-3 [40]'de de kar yükü hesabı kapsamlı bir şekilde verilmiștir. Ayrıca, zamanla çatı üzerindeki karın buz haline dönüşerek yoğunluğunun artması inceltilmiş uç bölgelerde hasar oluşumuna yol açmaktadır. Bundan dolayı literatürdeki çalışmalar detaylı incelenerek mevcut standartların iyileştirilmesi gerekmektedir. İnceltilmiş uç bölgesine yönelik çalışmalardan biri de Chen ve diğ. [41] tarafından yapılmışıtır. Bu çalışmada benzer geometri ve donatı oranı olan ancak farklı donatı yerleşim düzenine sahip inceltilmiş uçlarda donatı düzeninin kirişlerin kapasitesini etkilediğini tespit ederek ACI 318-08 [42] yönetmeliğinde verilen geleneksel tasarımın geliştirilmesi gerektiğini önermişlerdir. Lu ve diğ. [22] inceltilmiş kiriş uç bölgesinin kesmeye karşı dayanımını incelemiş ve Amerikan prefabrik yönetmeliğinin (PCI Design Handbook) revizyona ihtiyacı olduğunu belirterek yeni tasarım önerileri sunmuşlardır. Amerikan yönetmeliğine paralel olarak hazırlanan Türk Prefabrike Yapılar Yönetmeliği (TS 9967) için ise Gündoğan [43] TS 9967 ile PCI yönetmeliklerini karşılaştırmalı olarak incelemiş, eğilme, kesme ve askı donatısı miktarının TS 9967'de PCI’ya göre \%20 daha fazla olduğunu kesme sürtünme donatısının ise \%30-40 oranında daha az hesaplandığını belirtmiştir.

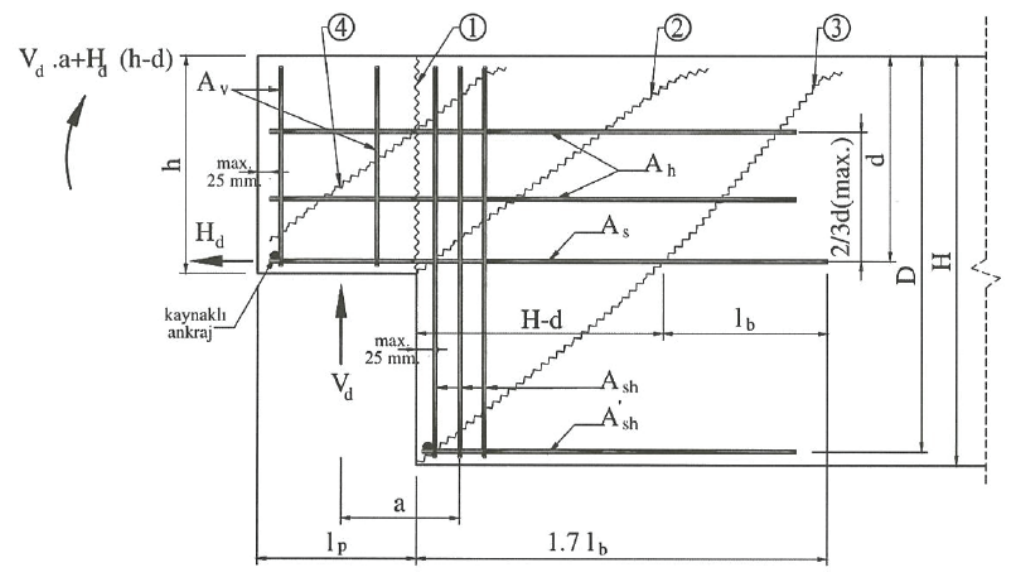

Şekil 4 - TS 9967 'ye uygun inceltilmiş uçlu prefabrike kiriş donatı yerleşimi ve çatlak oluşum mekanizması [37]

İnceltilmiş uçlu kirişlerde kesit tesirleri basit mesnetli kiriş de olduğu gibi hesaplanmaktadır. Fakat burada kiriş uçları inceltildiğinden mesnette oluşan kesme kuvvetinin büyük bir kısmı bu inceltilmiş bölgede yoğunlaştığından uç bölge detaylandırılması farklı yapılmaktadır. Bu 
kirişlerin çözümünde sırasıyla: kirişin üzerine gelen yük belirlenmekte, yük altında kirişin kesit tesir diyagramları çizilmekte, ve mesnet reaksiyonlarına göre kirişin uç kısmı boyutlandırılmaktadır. Boyutlandırma aşamasında kirişin her noktasındaki gerilme durumu önemli olduğundan dikkate alınmaktadır. Çünkü mesnet bölgesinde mafsallı birleşimden dolayı moment sıfırken, kesme kuvveti maksimum olmaktadır.

İnceltilmiş uçlu kirişler betonarme mesnetlere doğrudan oturabileceği gibi ayrıca çelik levha, korniyer ya da profil başlığa veya herhangi bir ara malzemeye de oturtulabilir. Mesnet bölgelerindeki kiriş uçları düşey $\left(\mathrm{V}_{\mathrm{d}}\right)$ ve yatay $\left(\mathrm{H}_{\mathrm{d}}\right)$ mesnet reaksiyonları ile ara malzemenin mesnet alanına paralel genişlemesiyle oluşacak çekme kuvvetlerini güvenle aktarıp taşıyabilmelidir. TS 9967'de ve BPEK-2018'de inceltilmiş uç bölgesine yönelik donatı düzeni ve oluşan çatlaklar Şekil 4'de gösterildiği gibi verilmektedir.

İnceltilmiş uca yerleştirilen donatılar, yükleme neticesinde oluşan çatlakları dik karşılayacak şekilde tasarlanmaktadır. Burada (1) ile gösterilen çatlak inceltilmiş uç kesişim noktasında doğrudan eğilmede çekme etkisiyle oluşmaktadır. (2) numara, inceltilmiş ucun başladığı noktadan itibaren diyagonal eğilme ve kesme şeklinde meydana gelmektedir. (3) numara ise inceltilmiş uç bölgesine geçmeden hemen önce diyagonal çatlak olarak gözlenmektedir. Son olarak (4) numara ise inceltilmiş uç bölgesinde oluşan diyagonal kesme çatlağ sınıflandırılmıştır. Şekil 4'de gösterilen 1 numaralı çatlağın engellenmesi için TS 9967 ve BPEK-2018, aşağıdaki denklemlerin kullanılarak donatı hesaplarının yapılması gerektiğini belirtmektedir. Burada BPEK-2018'in güncel olması sebebiyle aşağıdaki denklemler bu kaynak referans gösterilerek verilmiştir. İlk olarak Şekil 4'de gösterilen $\mathrm{A}_{\mathrm{s}}$ eğilme donatısı ve $A_{h}$ kesme sürtünme donatısı 1 numaralı çatlak boyunca kayma güvenliğini sağlamak amacıyla yerleştirilmektedir. Artan düşey yüke bağlı olarak uç bölgede oluşan moment $A_{s}$ donatısı ile karşılanmakta ve (1) bağıntısıyla hesap edilmektedir [38].

$$
A_{s}=A_{s f}+A_{n}=\frac{1}{f_{y d} x d} *\left[V_{d} x a+H_{d} x(h-d)\right]+\frac{H_{d}}{f_{y d}}
$$

Burada, a mesafesi(mm), $\mathrm{V}_{\mathrm{d}}$ kesme kuvvetinin $\mathrm{A}_{\text {sh }}$ donatı eksenine uzaklığını, $\mathrm{H}_{\mathrm{d}}$ 'nin $(\mathrm{kN})$ en az $0.20 \mathrm{~V}_{\mathrm{d}}$ olacağ, $\mathrm{h}(\mathrm{mm})$, inceltilmiş bölgedeki yüksekliği, $\mathrm{d}(\mathrm{mm})$, inceltilmiş bölgedeki faydalı kiriş yüksekliğini, $\mathrm{f}_{\mathrm{yd}}(\mathrm{MPa})$ ise enine donatının hesap dayanımı olarak ifade edilmektedir. $A_{s}$ donatıların ince ucun başından açıklığa doğru $(H-d)+l_{b}$ kadar uzaması gerektiği ve 3 nolu çatlağ $l_{b}$ kadar aşması gerektiği de ifade edilmektedir. Şekil 4'de 1 nolu olası çatlağın önlenmesi adına yerleştirilen donatılar $A_{s f}+A_{n}$ ve $A_{h}$ donatılarının toplamı (2) ve (3) bağıntılarında verilmiştir.

$$
\begin{aligned}
& A_{s f}=\frac{2}{3} x \frac{V_{d}}{f_{y d} x \mu_{e}} \\
& A_{n}=\frac{H_{d}}{f_{y d}}
\end{aligned}
$$


Burada $f_{\mathrm{yd}} ; \mathrm{A}_{\mathrm{sf}}, \mathrm{A}_{\mathrm{n}}$ ve $\mathrm{A}_{\mathrm{h}}$ donatılarının akma dayanımı olarak kullanılmaktadır.

Bağıntı (2)'deki sürtünme katsayısı ( $\mu_{\mathrm{e}}$ ), ve $\mathrm{A}_{\mathrm{h}}$ kesme sürtünme donatısı bağıntı (4) ve bağıntı

(5)'deki gibi hesaplanmaktadır.

$$
\begin{aligned}
& \mu_{e}=\frac{6.9 x \lambda^{2} x b x h x \mu}{V_{d}} \\
& A_{h}=0.5 x\left(A_{s}-A_{n}\right)
\end{aligned}
$$

Denklem 1'den bulunacak $A_{s}$ alanı ile Denklem 2 ve Denklem 3'ün toplamından elde edilecek $A_{s}$ alanı karşılaş̧ırılarak büyük olan değere göre inceltilmiş bölgedeki eğilme donatısı $\left(A_{s}\right)$ yerleşimi yapılmaktadır. Ayrıca bulunacak $A_{h}$ donatısı inceltilmiş uç yüksekliğinin (h) 2/3'üne en az iki sıra olarak yerleştirileceği belirtilmektedir. $A_{h}$ donatısının kesitteki bitim yerinin ise 1 numaralı çatlaktan sonra TS500 [44]'de belirtilen en az kenetlenme boyu $\left(l_{b}\right)$ kadar olması ifade edilmektedir.

Şekil 4'de inceltilmiş bölgede 4 numaralı çatlağı önlemek için yerleştirilen $A_{v}$ askı donatısı kiriş eksenine dik düzenlenmiş olmasından dolayı etriye olarak da isimlendirilmektedir. İnceltilmiş uç bölgesindeki donatıları birbirine bağlamak ve 4 numaralı çatlağı karşıllamak için bağıntı (6) kullanılarak askı donatısı hesaplanarak kapalı etriye olarak düzenlenmektedir.

$$
A_{v}=\frac{1}{2 x f_{y d}} x\left[\frac{V_{d}}{0.85}-0.65 x f_{c t d} x b x d\right]
$$

Şekil 4'de inceltilmiş ucun hemen bitiminde bulunan $A_{\text {sh }}$ askı donatısı 2 numaralı çatlağın oluşumunu önlemek amacıyla bağıntı (7)'deki gibi hesaplanmaktadır. Ash donatısı, kapalı düşey etriye şeklinde ya da kiriş çekme bölgesinde ana eğilme donatısının bükülebilir çapta olması durumunda, $90^{\circ}$ kıvrılıp gerekli ankraj boyunu sağlayacak biçimde oluşturulabilir.

$$
A_{s h}=\frac{V_{d}}{f_{y d}}
$$

Şekil 4'de 3 numaralı çatlağa paralel eğik beton basınç kuvvetinin yatay bileşenini alacak $\mathrm{A}_{\text {sh }}$ donatısı bağıntı (8)'deki gibi hesaplanmaktadır

$$
A_{s h}=A_{s h}^{\prime}=\frac{V_{d}}{f_{y d}}
$$

Şekil 4 incelendiğinde inceltilmiş kesitin büyük oranda kesme etkisinde olduğu bu nedenle oluşacak hasarın ani ve gevrek olacağı söylenebilir. Bundan dolayı oluşacak çatlaklara önlemlerin alınması gerektiği görülmektedir. Ayrıca TS 500'de verilen $l_{b}$, kenetlenme 
boyunu, $\mathrm{V}_{\mathrm{d}}$ ve $\mathrm{H}_{\mathrm{d}}$ ise çatlak oluşumlarına sebep olan düş̧ey ve yatay mesnet reaksiyonlarını temsil etmektedir. TS 9967 standardında ve BPEK-2018'de $\mathrm{A}_{\mathrm{s}}$ donatılarının inceltilmiş ucun başından açıklığa doğru en az $1.7 l_{b}$ boyunda olması gerektiği belirtilmektedir. Bununla beraber kenetlenme boyunun 3 numaralı çatlağı $l_{b}$ kadar aşması gerektiği de ifade edilmektedir. İnceltilmiş uçlu bir kiriş tasarımının TS 9967'ye ve BPEK-2018'e uygun olarak yapılabilmesi ancak yukarıdaki hesaplamalara uyulmasıyla mümkündür. Bununla birlikte belirtildiği üzere standartlara ve BPEK-2018'e uygun tasarımın yapılması durumunda dahi inceltilmiş bölgede hasarlar oluşabilmektedir. Literatürde yapı elemanlarının güçlendirilmesi için yapılan farklı güçlendirme yöntemleri ve güçlendirme malzemeleri mevcuttur [45-55]. Bunların ışı̆̆ında aşık kirişlerde oluşan hasarların giderilmesi adına bazı güncel alternatifler düşünülebilir. Ayrıca mevcut aşıkların iyileştirilmesi için literatürde yapılan çalışmalar incelendiğinde lifli polimer malzemeler ile aşık uçlarının güçlendirilebileceği de görülmektedir [56-69]. Literatürde güçlendirme amacıyla yaygın olarak kullanılan karbon fiber takviyeli polimer (CFRP) malzemelerin özellikle tercih edilme sebepleri arasında çeliğe göre ağırlıklarının beşte biri civarında olması ve çekme dayanımlarının 10 ile 14 kat fazla olması söylenebilir [70-73]. Daha çok kirişlerde sargılama amacıyla kullanılan bu lifler, uygulanma doğrultularına göre boyuna donatı veya enine donatı işlevi de görmektedirler.

\section{1. Çalışmanın Amacı ve Kapsamı}

$\mathrm{Bu}$ çalışmada prefabrike betonarme aşık kirişlerinin en zayıf halkası olarak kabul edilen inceltilmiş uç bölgelerinde oluşacak hasarları önlemek için bir dizi parametrik çalışma yapılmıştır. İlk olarak yürürlükte olan standartlara uygun olan ve olmayan birer adet aşık kirişinin deneyleri gerçekleştirilmiştir. Ardından yine standarda uygun bir adet aşık kiriş inceltilmiş uç hasarının önlenmesi amacıyla CFRP ile güçlendirilerek test edilmiştir. Daha sonra ABAQUS programıyla modellenen aşıklardan elde edilen numerik sonuçlar ile deneysel çalışma sonuçları karşılaştırılarak modeller doğrulanmıştır. Modellemelerin ardından aşıkların mekanik özellikleri ile güçlendirme alternatiflerine bağlı bir dizi parametrik çalışma numerik olarak gerçekleştirilmiştir. Parametrik çalışmada; özellikle mevcut aşıklarda beton basınç dayanımı, donatı çekme dayanımı ve aşık kirişlerin üretiminde kullanılan öngerme seviyesinin tasarlanandan farklı olabileceği düşüncesiyle her biri parametre olarak düşünülmüştür. Literatürde benzer parametrelerin baz alındığı öngerilmeli kiriş deneyleri mevcuttur [74-78]. Ayrıca CFRP uygulaması ile güçlendirilen ve yönetmeliğe göre tasarlanmayan aşığın davranışı da yine parametrik çalışma kısmında incelenmiştir. $\mathrm{Bu}$ çalı̧̧manın ana motivasyonunu,

- ABAQUS programıyla modellenen aşıklardan elde edilen sonuçlar ile deneysel çalı̧̧ma sonuçları karşılaştırılarak modellerin numerik olarak doğrulanıp doğrulanamayacağını sınamak,

- TS 9967 ve BPEK-2018'e göre önerilen donatı ve beton sinıfi, ön germe halat kapasitesi gibi parametrelerin değiştirilmesi durumunda kesme kapasitesinde ve hasar gelişiminde meydana gelecek olan farklılığı analiz etmek,

- Uygulamada aşık kirişleri için dikkate alınan standart detayların yapılan deneysel ve numerik çalışmalar ile kontrol edilmesi ve BPEK-2018' de ve TS500'de belirtilen kenetlenme boyu $\left(\mathrm{l}_{\mathrm{b}}\right)$, ask1 donatısı $\left(\mathrm{A}_{\mathrm{sh}}\right)$ parametrelerinin incelenerek yeni detaylar üretebilmek, 
- İnceltilmiş uçlu kirişlerin kar yükü ve zamanla oluşan buz yükü altında hasar aldığ ve bu hasarın üretim aşamasında alınacak önlemler ile veya aşık kaldırılmadan (sonradan) yapılması gereken CFRP ile güçlendirme alternatifi ile nasıl giderilmesi gerektiğini araştırmak, inceltilmiş uçlu kirişlerin sonradan güçlendirilmesi adına CFRP ile yapılan deneysel ve numerik çalışmalar ile pratik ve etkili bir güçlendirme alternatifi sunmak, oluşturmaktadır.

\section{MATERYAL VE METOD}

\subsection{Deneysel Çalışma}

Bu çalışmada iki adet aşık uç bölge donatı detaylandırması, TS 9967 normlarına ve BPEK2018'e uygun (D1) olması ya da olmaması (D2) durumuna göre deneysel olarak dikkate alınmıştır. D2 numunesinin uygun olmaması ask1 donatısı sayısının ve kenetlenme boyunun azaltılması ile gerçekleştirilmiştir. D2 numunesinin deneysel ve numerik olarak incelenmesinin nedeni ise eski tip yapılardaki mevcut eksikliklerin değerlendirilmek istenmesidir. Deneysel çalışmada D1 numunesinde oluşan hasar inceltilmiş uç bölgesinde kesme hasarı olarak meydana gelmiştir. Bundan dolayı TS 9967'ye ve BPEK-2018'e uygun (D3) bir adet aşığın inceltilmiş uç bölgesi CFRP ile sargılanarak (güçlendirilerek) deneysel testi gerçekleştirilmiştir [79]. Sonuç olarak elde edilen üç adet aşığın düşey yükler altında deneysel çalışması yapılmışıtır.

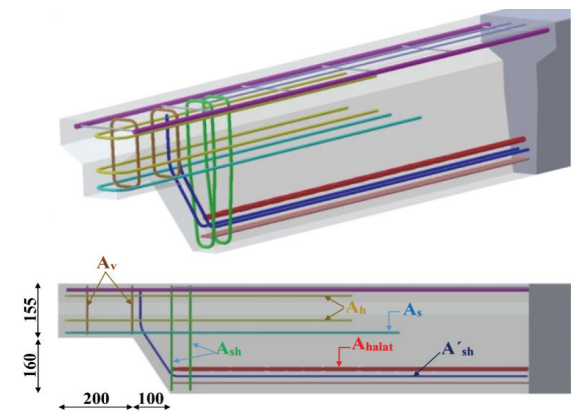

a) D1 ve D3:TS 9967'ye ve BPEK2018 'e uygun donatı düzeni
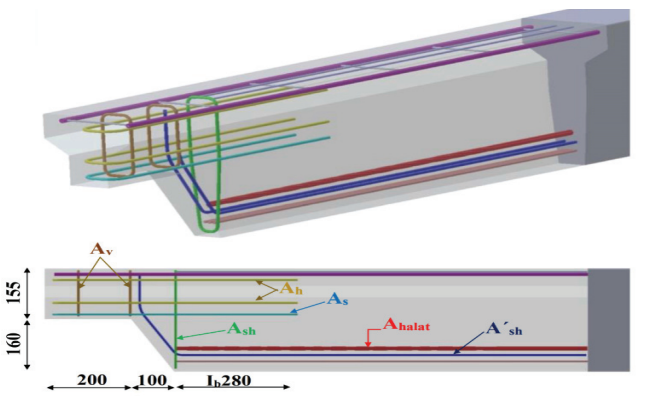

b) D2:TS 9967'ye ve BPEK-2018'e uygun olmayan donatı düzeni

Şekil 5 - TS 9967'ye ve BPEK-2018'e uygun ve uygun olmayan donatl detayl

Deneylerde kullanılan yük hücresinin kapasitesi ve boyutları düşünülerek test edilecek aşık boyları $320 \mathrm{~cm}$ olarak seçilmiştir. Uygulamada aşı üzerinde var olan yayılı yük deneysel olarak çok pratik olmadığından dolayı 2 noktadan noktasal yük ile elemanın kesme ve moment davranışları yayılı yüke benzetilmeye çalışılmışıı. Çalışmada incelenen bölge inceltilmiş uç bölgesi olduğu için ilk olarak bu bölgelerin hasar görmesi amaçlanmıştrr. Kesme açıklığı / aşık kirişi faydalı yükseklik (av/d) oranı 2.4 olarak dikkate alınmış ve bu sayede inceltilmiş uç bölgede kesme hasarı oluşumu sağlanmıştır. Aşık kirişlerin üretimi esnasında alınan üç adet silindir beton numunesinin eksenel basınç testi sonucu sırasıyla 31.4 $\mathrm{MPa}, 28.8 \mathrm{MPa}$, 30.3 MPa olarak ve bunların aritmetik ortalaması da $30.16 \mathrm{MPa}$ olarak 
hesaplanmıştır.Deneysel çalışmada D1 ve D3 olarak tasarımı yapılan aşıklarda ortalama B420c tipinde $2 \Phi 8$ boyuna donatılar ile 1 adet $1 / 2$ " $(1.27 \mathrm{~cm}$ çapında) öngerme halatı tasarımda dikkate alınmıştır. Ayrıca Şekil 4'de gösterilen 2 numaralı çatlağın oluşumunu engellemek için uç bölgelerde 2 adet $\Phi 8$ askı donatısı $\left(\mathrm{A}_{\text {sh }}\right)$ kullanılmıştır.

D2 aşık numunesinde ise ask1 donatısı 1Ф8'e düşürülmüştür. Bununla beraber D2 numunesinde 3 numaralı çatlağın ilerlemesini engelleyecek olan $A^{\prime}$ sh donatısının boyu önerilen $1.7 \mathrm{l}_{\mathrm{b}}(476 \mathrm{~mm})$ yerine $1.0 \mathrm{l}_{\mathrm{b}}(280 \mathrm{~mm})$ olarak sınırlandırılmıştır. Şekil 5'de D1, D2 ve D3 tipi aşıkların donatı düzeni gösterilmiş, Çizelge 1'de ise donatı adetleri ve kenetlenme boy bilgileri verilmiştir. Burada kullanılan iki aşık (D1-D3/D2) arasındaki tek farkın askı donatısı sayısı ile kenetlenme boy $\left(l_{b}\right)$ miktarı olduğu görülmektedir.

Çizelge 1 - D1, D2 ve D3 tipi aşıkların donatı düzeni

\begin{tabular}{|c|c|c|}
\hline Donatı Tipi & $\begin{array}{c}\text { TS 9967'ye ve BPEK- } \\
\text { 2018'e uygun } \\
\text { (D1-D3) }\end{array}$ & $\begin{array}{c}\text { TS 9967'ye ve BPEK- } \\
\text { 2018'e uygun değil } \\
\text { (D2) }\end{array}$ \\
\hline Kesme Sürtünme Donatısı $\left(\mathrm{A}_{\mathrm{h}}\right)$ & $2 \phi 8$ & $2 \phi 8$ \\
\hline $\begin{array}{c}\text { İnceltilmiş Bölgedeki Eğilme } \\
\text { Donatısı }\left(A_{s}\right)\end{array}$ & $2 \phi 8$ & $2 \phi 8$ \\
\hline $\begin{array}{c}\text { İnceltilmiş Bölge Dişındaki } \\
\text { Eğilme Donatısı }\left(A^{\prime}{ }_{s h}\right)\end{array}$ & $2 \phi 8$ & $2 \phi 8$ \\
\hline Askı Donatısı $\left(A_{\text {sh }}\right)$ & $2 \phi 8$ & $1 \phi 8$ \\
\hline Ön germe halatı & $1 / 2$ ' (inch) & $1 / 2$ ''(inch) \\
\hline $\begin{array}{c}\text { İnceltilmiş bölgedeki etriye } \\
\text { donatıs1 (Av) }\end{array}$ & $2 \phi 8$ & $2 \phi 8$ \\
\hline Kenetlenme boyu $\left(l_{b}\right)$ & $476 \mathrm{~mm}$ & $280 \mathrm{~mm}$ \\
\hline
\end{tabular}

Yapılan deneysel çalışmalar Konya Teknik Üniversitesi Mühendislik ve Doğa Bilimleri Fakültesi İnşaat Mühendisliği Bölümü, Deprem Araştırma Laboratuvarı'nda 500 kN kapasiteli rijit çelik yükleme çerçevesi kullanılarak düşey yükleme düzeneğinde gerçekleştirilmiştir. Çalışma kapsamında kullanılan aşıklar aynı zamanda üretildiği için malzeme özellikleri aynıdır. Deney esnasında bilgisayar destekli 8 kanallı veri okuma sistemi kullanılarak, gerekli yük ve yer değiştirme okumaları yapılmış ve kayıt altına alınmıştır. Deney sırasında düşey yük ölçümleri yük ölçer ile, düşey yer değiştirmeler ise LVDT kullanılarak yapılmıştır. Yük hücresinin kapasitesi 300 kN'dur. Deneylerde yük protokolü, düşey monotonik yükleme ile $10 \mathrm{kN}$ 'luk artışlar şeklinde uygulanmıştır. Yük kontrollü olarak sürdürülen deneyler aşık kirişlerinde kesme hasarı ile ani ve gevrek bir şekilde sonlanmıştır. Monotonik her yüklemede kısa bir süre deney üzerindeki çatlakların işaretlenmesi için beklenilmiştir. Deneysel çalışmada oluşan hasarlar D1 numunesi için göçmeye yakın uç bölgede meydana gelirken D2 ve D3 numunesi için inceltilmemiş bölgede meydana gelmiştir. Çalışmanın numerik modelleme kısmı ön plana çıkarılmak istendiğinden deneysel 
çalışma sonuçları için gerekli ve yeterli şekil ve çizimler ile birlikte deney düzeneği Şekil 6'da, karşılaştırma grafiği Şekil 7'de verilmiştir.

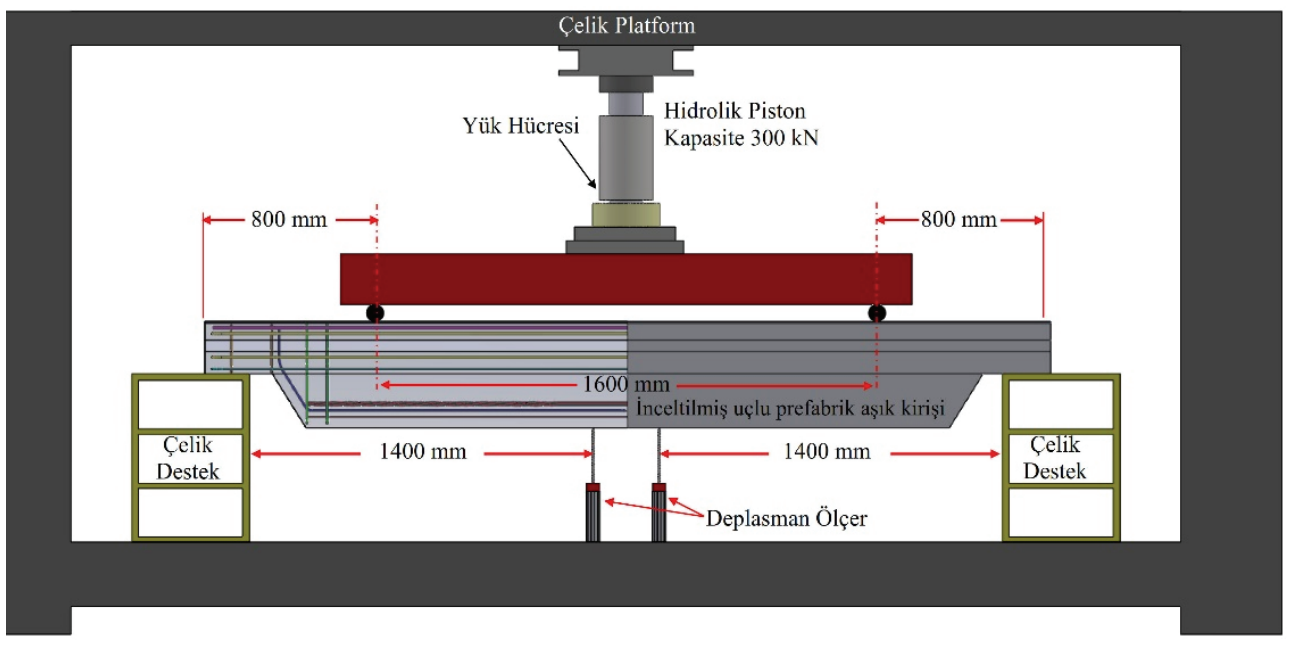

Şekil 6 - Aşık yükleme deney düzeneği

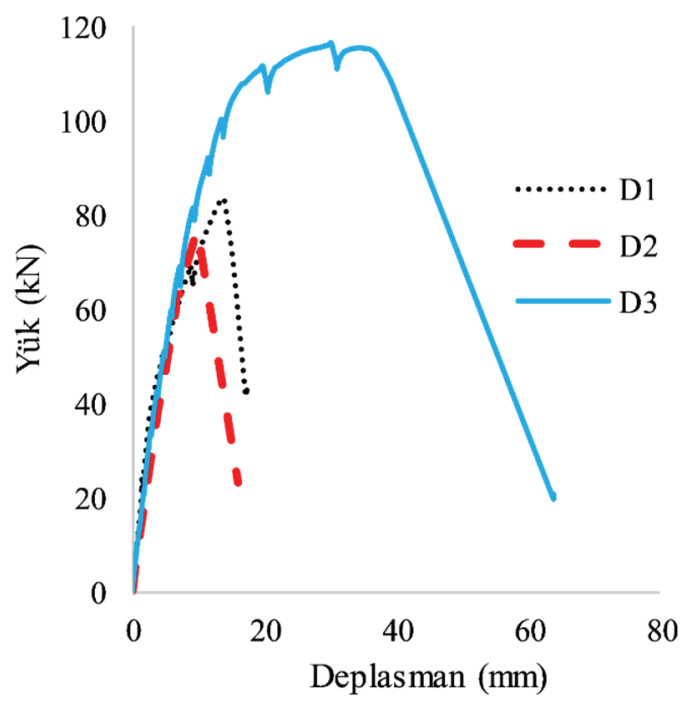

Şekil 7 - Deney sonuçlarının karşılaştırılması

Şekil 7'de deneysel çalışması yapılan üç numunenin karşılaştırılması, Şekil 8'de ise her bir numunenin deneysel makro hasar analizleri gösterilmiştir. Bunlardan ilki D1 numunesidir. D1 numunesinde yük $83.5 \mathrm{kN}$ ve deplasman değeri $13.8 \mathrm{~mm}$ olduğu anda inceltilmiş uç bölgesinde kesme hasarı ile aşık kirişi göçme konumuna ulaşmıştır. D2 numunesinde ise 
sonuç hasarı, yükün $76.3 \mathrm{kN}$ ve düşey deplasmanın $9.7 \mathrm{~mm}$ olduğu anda inceltilmiş bölge dışında ani kesme hasarı şeklinde meydana geldiği görülmüştür. İnceltilmemiş bölgedeki eğilme donatılarının $\left(\mathrm{A}_{\text {sh }}^{\prime}\right)$ koptuğu gözlenmiştir. Eğilme bölgesinde bulunan ön germe halatında ise herhangi bir kopma gözlenmemiştir. Bu durum aslında inceltilmemiş bölgeye yerleştirilen fazladan bir adet $\mathrm{A}_{\text {sh }}$ donatısının önemini göstermektedir. Son olarak D3 numunesinin CFRP ile üç yüzeyinin mesnet bölgesi de dahil $U$ şeklinde güçlendirildiği numunede göçme hasarı maksimum yük taşıma kapasitesinin $116.4 \mathrm{kN}$ ve deplasman değerinin $39 \mathrm{~mm}$ olduğu anda gerçekleşmiştir. Nihai hasarın kesmeli eğilme olarak meydana geldiği aşık kirişin inceltilmiş uç bölgelerinde CFRP'nin betona deney sonuna kadar tam bir aderans ile bağlı olduğu görülmüştür. Ayrıca uygulamada aşık kirişlerinin eğik çatı kirişinden (makaslardan) ayrılmadan (de-monte olmadan) aşığı alttan saracak şekilde U tipi CFRP ile güçlendirilmesi oldukça zordur. Bu çalışmada tam kapasite ile CFRP'nin etkisi görülmek istendiğinden bu tip bir güçlendirme tercih edilmiştir. Gerçek uygulamada mesnet bölgelerinde yapılacak bu güçlendirmenin aşığın kaldırılmadan uygulanması mümkün olmayacaktır. Bunun için numerik analiz kısmında aşıkların yerinden kaldırılmaması adına farklı tip güçlendirme modelleri numerik olarak analiz edilmiş ve daha pratik ve etkili güçlendirme alternatifler de önerilmiştir.

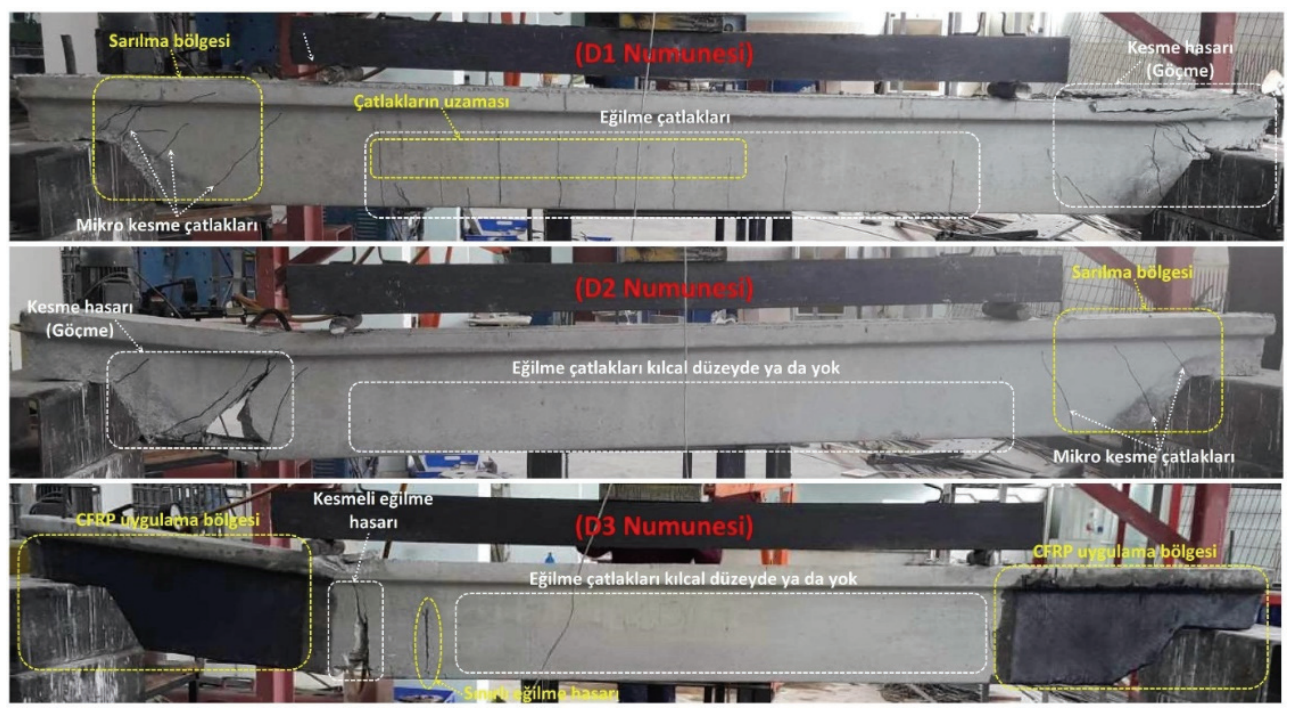

Şekil 8 - Deneysel çalışma sonrası inceltilmiş uçlu kirişlerin makro hasar analizleri

\subsection{Analitik Çalışma}

Literatürde inceltilmiş uçlu kirişler için önerilen analitik çalışmalarda kafes kiriş (strut and tie) modelleri üzerine yapılanlar ön plana çıkmaktadır. Genel olarak kafes kiriş (strut and tie, STM) modeli üç ana bileşenden oluşmaktadır. Bunlar sırasıyla basıncı karşılayan (strut), çekmeyi karşılayan (tie) çubuklar ile basınç ve çekme çubukların birleşim noktalarını temsil eden dügüum bağlantı (node) elamanlarıdır [80]. STM sadece akma kriterlerinin ve sistem dengesinin karşılanmasını gerektirir. Gerinim uyumluluğu gerektirmeyen bir model sunmaktadır. $\mathrm{Bu}$ durum alt sınır plastisite methoduna karşılık gelmektedir [81, 82]. 
İnceltilmiş uçlu aşık kirişlerin muhtemel STM modelinin tanımlanması için bir çok metod geliştirilmiştir. Bu çözümlerin hepsi elastik çözümlere dayanmaktadır. İnceltilmiş uçlu kirişler için en yaygın kullanılan STM'ler takviye düzenine bağlı olarak üç kategoride değerlendirilmiş̧ir (Şekil 9). Bunlar sırasıyla diyagonal, dikey ve kombinasyon modelleridir. İnceltilmiş uçlu aşıklara yönelik Avrupa ve ABD'de kafes kiriş modelleri üzerine farklı eğilimler olduğu görülmektedir. Avrupa'da, inceltilmiş uçlu kirişler üzerinde var olan yükü inceltilmemiş bölgeye aktarmak için diyagonal bir donatı ile kafes kiriş (strut and tie) modeli daha çok kullanılmaktadır (Şekil 9a) [82, 83] . Bununla birlikte ABD'de ise inceltilmemiş bölgeye yerleştirilen dikey donatılar ile inceltilmiş uç bölgeye uzanan yatay takviye donatıları daha yaygın olarak tercih edilmektedir. $\mathrm{Bu}$ durum dikey kafes kiriş (strut and tie) modelinin yaygın olduğunu göstermektedir (Şekil 9b-c-d) [84-86]. Ayrıca inceltilmiş uçlu kirişler için daha karmaşık kombinasyonlarda kafes kiriş (strut and tie) modeli literatürde önerilmektedir (Şekil 9e) [82, 87-89].

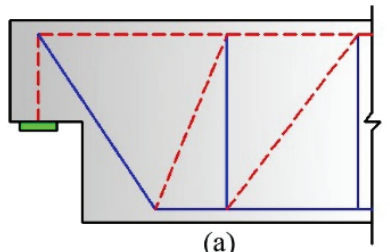

(a)

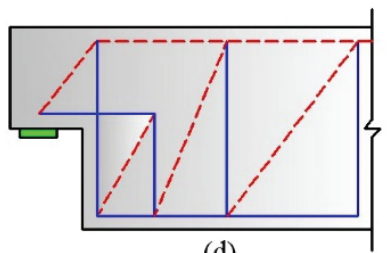

(d)

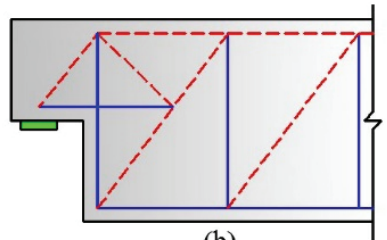

(b)

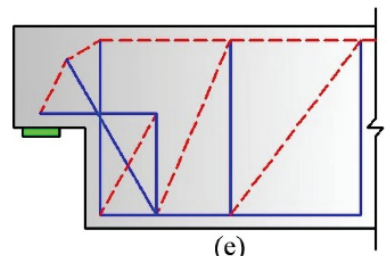

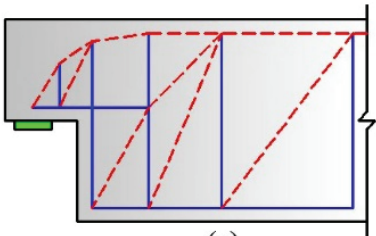

(c)

Basınç çubuğu

Çekme çubuğu

Şekil 9 - Inceltilmiş uçlu kirişlerde yaygın kullanılan kafes kiriş modelleri: a) diyagonal model, b-c-d) dikey model, e) kombinasyon tipi model

Şekil 9'dan da görüldüğü üzere literatürde kafes kiriş modelleri için yapılan analitik çalışmalarda elastik çalışmalara yoğunlaşılmıştır. Gelişen teknoloji ile numerik çalışmalara olan ilgi ise gün geçtikçe artmaktadır. Numerik çalışmalar sayesinde yorucu ve maliyetli deneyler yapılmadan birçok araştırma yürütülebilmektedir [90]. Bu çalışmada numerik analizler sonlu elemanlar paket programı olan ABAQUS kullanılarak yapılmıştır. ABAQUS programı zor ve karmaşı problemleri yeterince güvenli sunması ile bu çalışmanın odak noktasını oluşturmaktadır.

$\mathrm{Bu}$ çalışmada, ilk olarak deneysel çalışmadaki D1, D2 ve D3 numunelerin doğrulaması numerik olarak sırasıyla N1, N2 ve N3 modelleri oluşturularak gerçekleştirilmiştir. Daha sonra 10 farklı yeni numerik model ile TS 9967 ve BPEK-2018'e uygun olmayan aşıklar için analiz yapılmıştır. Yapılan analiz parametreleri Tablo 4'de verilmiştir. Çalışmada mevcut yapılarda bulunan aşıklardaki standartlara uygun olmayan tasarım veya üretim hatalarına dikkat çekilmek istenmiştir. Bunun için aşıkların uç bölgesinde kesme davranışını etkileyen parametreler araştırılmış ve güçlendirilmesi için öneriler verilmiştir. Numerik çalışma için 3 boyutlu elamanlar kullanılmıştır. Numerik model, deneyin sınır şartlarını ve yüklemeyi doğru 
temsil edecek şekilde tasarlanmıştır. Yükleme, deney sırasında aşıklara kuvvet uygulanan alanlara deplasman verilerek sağlanmıştır. Yüksek deformasyonların etkisini katmak için doğrusal olmayan geometri opsiyonu aktif edilmiştir. Ayrıca doğrusal olmayan malzeme modelleri tanımlanmıştır. Betonun modellemesi için sekiz düğüm noktalı üç boyutlu katı elemanlar (C3D8R) kullanılmıştır. Çelik donatılar ve çelik halatlar üç boyut iki düğüm noktalı kafes elemanları (T3D2) kullanılarak modellenmiştir. Betonarme için $20 \mathrm{~mm}$ eleman ağ1 boyutu seçilirken çelik donatılar ve çelik halat için $10 \mathrm{~mm}$ eleman ağ kullanılmıştır. Kullanılan modelin eleman ağı dağılımı ve donatı yerleşimi Şekil 10'da gösterilmiştir.

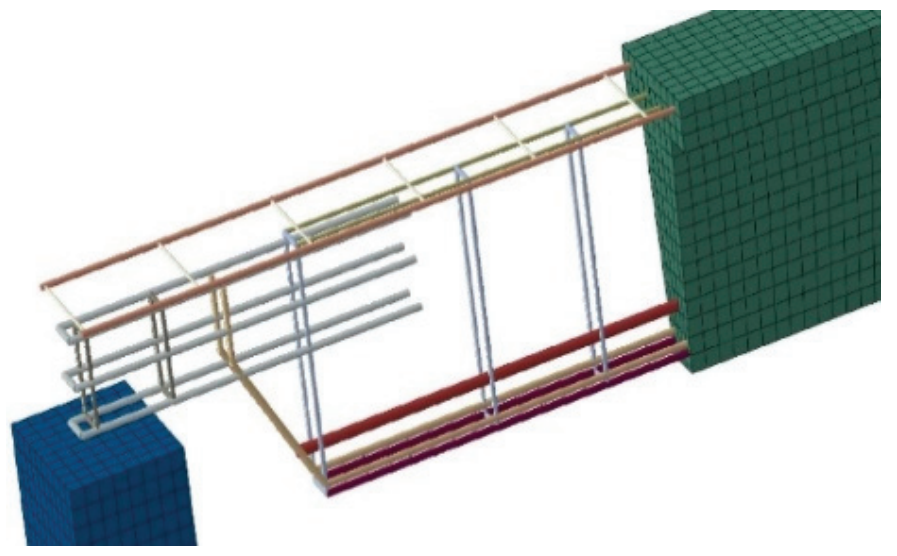

Şekil 10 - Numerik model

Sonlu elemanlar metodu ile gerçekçi sonuçlar elde etmek için malzeme modellerinin doğru bir şekilde tanımlanması gerekmektedir. Bu çalışmada beton modellemesi için beton plastik hasar modeli kullanılmıştır. Beton plastik hasar modeli için betonun basınç ve çekme dayanımı, elastisite modülü, çatlama ve ezilme hasar dayanımlarının tanımlanması gerekmektedir. Ayrıca Çizelge 2'de verilen parametreler de betonun numerik olarak modellenmesi için kullanılmıştır.

Çizelge 2 - Beton modelinde kullanulan parametreler

\begin{tabular}{cccc}
\hline Dilatasyon Açısı & Eksantriktik & fb0/fc0 & $\mathrm{K}$ \\
\hline 31 & 0.1 & 1.16 & 0.667 \\
\hline
\end{tabular}

fb0/fc0: Çift yönlü yükleme oranı

Bu çalışmada Dere [91] tarafından önerilen beton modeli kullanılmıştır. Basınç gerinim ve gerilme ilişkisi (9) numaralı bağıntı kullanılarak elde edilmiştir. Burada $\sigma_{c}$ basınç gerilimini, $\varepsilon_{\mathrm{c}}$ basınç gerinimini, $\mathrm{f}_{\mathrm{c}}$ tek eksenli basınç gerilimini, $\varepsilon_{\mathrm{co}}$ tek eksenli basınç gerinimini temsil eder ve $n$ ise (10) numaralı bağıntı kullanılarak elde edilmiştir. 


$$
\frac{\sigma_{c}}{f_{c}}=\frac{n\left(\frac{\varepsilon_{c}}{\varepsilon_{c o}}\right)}{(n-1)+\left(\frac{\varepsilon_{c}}{\varepsilon_{c o}}\right)^{n}}
$$

$$
n=0.0004 f_{c}+1.0
$$

Çekme gerinim ve gerilim ilişkisi maksimum çekme kuvvetine kadar elastik ve bu noktadan sonra plastik davranış sergiler. Çekme gerinim ve gerilim ilişkisi (11) ve (12) numaralı bağıntılar kullanılarak elde edilmiştir.

$$
\begin{aligned}
& \sigma_{t}=f_{t}\left(\frac{\varepsilon_{t o}}{\varepsilon_{t}}\right)^{0.4} \\
& \varepsilon_{t o}=\frac{f_{t}}{E_{c}}
\end{aligned}
$$

Betondaki hasar, beton basınç hasar parametresi $\left(d_{c}\right)$ ve beton çekme hasar parametresi $\left(d_{t}\right)$ kullanılarak tespit edilir. Bu parametreler de 0 değeri hasarsız betonu, 1 değeri ise tamamen hasarlı betonu temsil eder. Beton basınç hasar parametresi (13) numaralı bağıntıdan ve beton çekme hasar parametresi (14) numaralı bağıntıdan elde edilmiştir.

$$
\begin{aligned}
& d_{c}=1-\frac{\sigma_{c} E_{c}^{-1}}{\varepsilon_{c}^{p l}\left(1 / b_{c}-1\right)+\sigma_{c} E_{c}^{-1}} \\
& d_{t}=1-\frac{\sigma_{t} E_{c}^{-1}}{\varepsilon_{t}^{p l}\left(1 / b_{t}-1\right)+\sigma_{t} E_{c}^{-1}}
\end{aligned}
$$

$30 \mathrm{MPa}$ basınç dayanımına sahip betonun modellenmesi için kullanılan basınç dayanımı, çekme dayanımı, basınç hasar parametresi ve çekme hasar parametresi Şekil 11'de tanımlanmıştır. Betonun maksimum yüke ulaştıktan sonraki davranışını incelemek ve muhtemelen oluşacak olan yakınsama problemlerinin önüne geçmek için Hognestad beton gerilme-deformasyon eğrisi [92] birçok araştırmacı tarafından ABAQUS modellerine yüksek gerinim (strain) değerlerine kadar tanımlanmaktadır [93-97]. 
Çelik ise B420c malzeme özelliklerine göre modellenmiştir. Akma dayanımı $420 \mathrm{MPa}$, çekme dayanımı $560 \mathrm{MPa}$, elastisite modülü $200 \mathrm{GPa}$ ve poisson oranı 0.3 olarak alınmıştır. ABAQUS'de malzeme modeline gerçek gerinim ve gerilme değerlerinin tanımlanması gerekmektedir. (15) ve (16) numaralı bağıntılar kullanılarak gerçek gerinim ve gerilme değerlerine dönüştürülmüştür. Halat için ise akma dayanımı $1500 \mathrm{MPa}$ olarak tanımlanmıştır. Modelde halata öngerme sıcaklık verilerek uygulanmıştır.
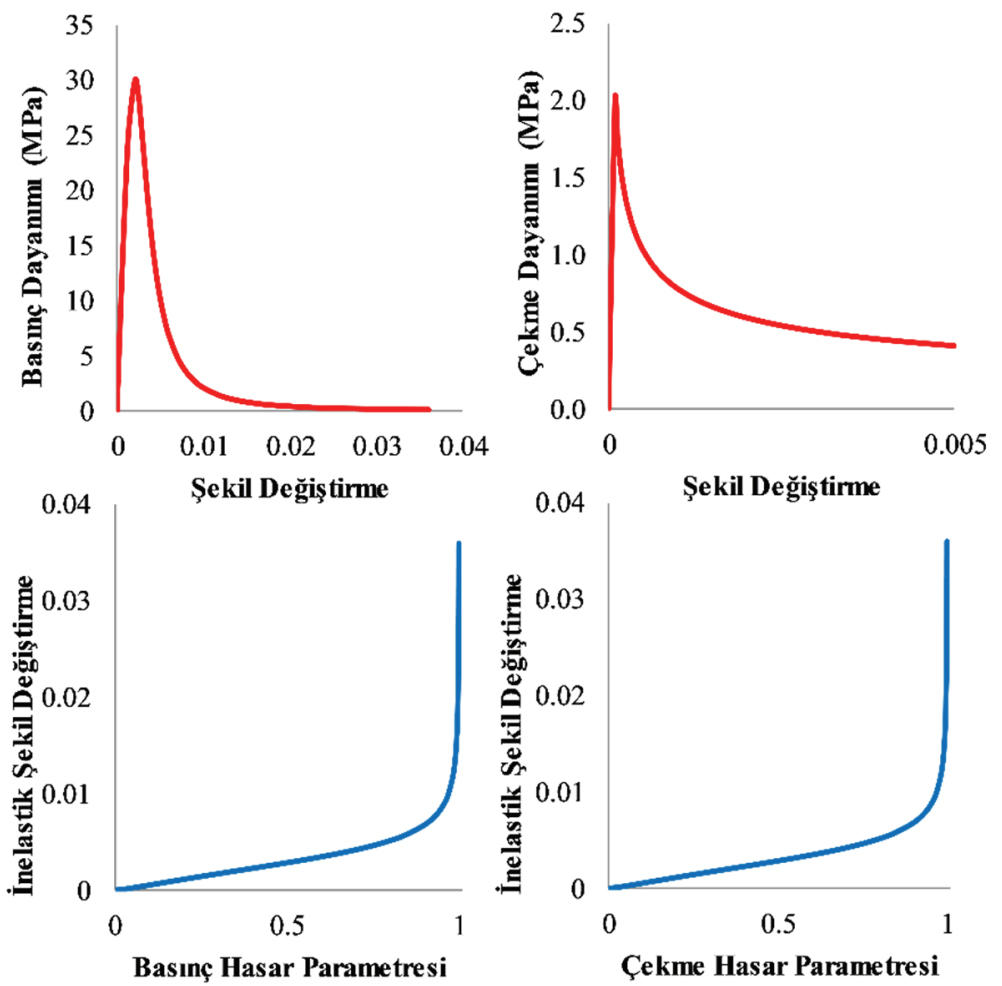

Şekil 11 - Beton modeli için gerekli parametreler

$$
\begin{aligned}
& \varepsilon_{T}=\ln (1+\varepsilon) \\
& \sigma_{T}=\sigma(1+\varepsilon)
\end{aligned}
$$

Deneysel çalışması yapılan bir adet CFRP ile güçlendirilmiş D3 aşık eleman da numerik olarak N3 ABAQUS'de modellenmiştir. CFRP modellemesi için Hashin hasar teorisi [98] kullanılmıştır. CFRP malzeme modellemesi için Gemi ve diğ. [79] çalışmasında kullanılan 
Çizelge 3 - Elyaf modelinde kullanilan parametreler

\begin{tabular}{lcc}
\hline Parametreler & Kısaltma & Değer \\
\hline Elyaf doğrultusunda elastisite modülü & $\mathrm{E}_{1}(\mathrm{GPa})$ & 70000 \\
Elyaf doğrultusuna dik doğrultuda elastisite modülü & $\mathrm{E}_{2}(\mathrm{GPa})$ & 6000 \\
Poisson oranı & $\mathrm{V}_{12}$ & 0.30 \\
Kayma modülü & $\mathrm{G}_{12}(\mathrm{GPa})$ & 3000 \\
Elyaf doğrultusunda çekme mukavemeti & $\mathrm{X}^{\mathrm{T}}(\mathrm{MPa})$ & 1450 \\
Elyaf doğrultusunda basma mukavemeti & $\mathrm{X}^{\mathrm{C}}(\mathrm{MPa})$ & 1550 \\
Elyaf doğrultusuna dik doğrultuda çekme mukavemeti & $\mathrm{Y}^{\mathrm{T}}(\mathrm{MPa})$ & 50 \\
$\begin{array}{l}\text { Elyaf doğrultusuna dik doğrultuda } \\
\text { basma mukavemeti }\end{array}$ & $\mathrm{Y}^{\mathrm{C}}(\mathrm{MPa})$ & 70 \\
Kayma mukavemeti & $\mathrm{S}(\mathrm{MPa})$ & 40 \\
\hline
\end{tabular}

Çizelge 4 - Numerik modellerin özellikleri

\begin{tabular}{|c|c|c|c|c|c|c|}
\hline $\begin{array}{c}\text { Numerik } \\
\text { model }\end{array}$ & $\begin{array}{c}\text { TS9967'ye } \\
\text { ve BPEK- } \\
2018 \text { 'e } \\
\text { uygunluk }\end{array}$ & $\begin{array}{c}\text { Beton } \\
\text { dayanımı } \\
(\mathrm{MPa})\end{array}$ & $\begin{array}{c}\text { Çelik } \\
\text { dayanımı } \\
(\mathrm{MPa})\end{array}$ & $\begin{array}{l}\text { Öngerme } \\
(\mathrm{kN})\end{array}$ & $\begin{array}{c}\text { FRP } \\
\text { güçlendirme }\end{array}$ & $\begin{array}{l}\text { Donatida } \\
\text { değişiklik }\end{array}$ \\
\hline $\mathrm{N} 1^{*}$ & Evet & 30 & 420 & 140 & Yok & - \\
\hline $\mathrm{N} 2^{* *}$ & Hayır & 30 & 420 & 140 & Yok & - \\
\hline $\mathrm{N} 3^{* * *}$ & Evet & 30 & 420 & 140 & Var (U sargilama) & - \\
\hline N4 & Hayır & 20 & 420 & 140 & Yok & - \\
\hline N5 & Hayır & 40 & 420 & 140 & Yok & - \\
\hline N6 & Hayır & 30 & 500 & 140 & Yok & - \\
\hline N7 & Hayır & 30 & 420 & 200 & Yok & - \\
\hline N8 & Hayır & 30 & 420 & 100 & Yok & - \\
\hline N9 & Hayır & 30 & 420 & 140 & $\begin{array}{c}\text { Var (Yan Tam } \\
\text { Sargilama) }\end{array}$ & - \\
\hline N10 & Hayır & 30 & 420 & 140 & $\begin{array}{c}\text { Var (Yan Dik } \\
\text { Şerit Sargılama) }\end{array}$ & - \\
\hline N11 & Hayır & 30 & 420 & 140 & $\begin{array}{l}\text { Var (Yan Eğik } \\
\text { Şerit Sargılama) }\end{array}$ & - \\
\hline N12 & Hayır & 30 & 420 & 140 & Yok & $\begin{array}{c}\mathrm{A}_{\mathrm{v}} \text { yeri } \\
\text { değiştirildi }\end{array}$ \\
\hline N13 & Hayır & 30 & 420 & 140 & Yok & $\begin{array}{l}\text { lb boyu } \\
\text { k1satıld1 }\end{array}$ \\
\hline
\end{tabular}

*: D1 **:D2 ve ***:D3'e özdeş modellerdir. 
kompozit malzemenin özellikleri tanımlanmış ve Çizelge 3'de verilen malzeme özellikleri kullanılmıştır. CFRP'nin modellenmesi dört düğüm noktalı kabuk elemanları (S4R) kullanılarak yapılmıştır. Gemi ve diğ. [79] prefabrike aşıklarda görülen kesme hasarını engellemek için aşıkların uç kısımlarına $\left[ \pm 45^{\circ}\right]$ konfigürasyonunda tabakalı CFRP kompozit kullanmışlardır. Yapılan deneysel çalışmada elyaf matris ara yüzey ayrılması (debonding) ve tabaka ayrılması (delaminasyon) hasarı gözlenmemiş̧ir. Delaminasyon ve debonding ana hasar modu olmadığı durumlarda, FRP ve beton mükemmel yapışacak şekilde modellenebilir. Birçok araştırmada [93, 99-104] FRP ve beton mükemmel yapışacak şekilde modellenmiş ve deneysel sonuçlara benzer sonuçlar elde edilmiştir. Bu çalışmada da deneysel çalışmada debonding ve delaminasyon hasarı gözlenmediği için, numerik modelde CFRP betona mükemmel bir şekilde yapıştııılmış ve yapıştırıcı ayrıca modellenmemiştir. İnceltilmiş uçlu kirişlere ilave CFRP ankraj modellemesi de yapılmamıştır.

$\mathrm{Bu}$ çalışma kapsamında 3 tanesi doğrulama modeli olmak üzere toplam 13 adet numerik model tasarlanmıştır. İlk olarak TS 9967'ye ve BPEK-2018'e uygun D1 numunesi numerik (N1) olarak doğrulanmıştır. Daha sonra TS 9967'ye ve BPEK-2018'e uygun olmayan D2 numunesi numerik (N2) olarak doğrulanmıştır. Son olarak TS 9967'ye ve BPEK-2018'e uygun D3 numunesi numerik (N3) olarak doğrulanmıştır. Ardından sırasıyla Çizelge 4'de verilen parametrelere göre bir dizi numerik çalışma gerçekleştirilmiştir. Yapılan numerik çalışmaların bir kısmı (N4-N8) aşıkların üretim aşamasında yapılabilecek müdahalelere yönelik iken diğer bir kısmı (N9-N11) sahada montajı tamamlandıktan sonra güçlendirilmesi gereken aşıklar için düşünülmüsşür. Ayrıca yönetmeliklerdeki donatı düzenini iyileştirmek için birtakım çalışmalar (N12-N13) yapılmıştır.

\section{BULGULAR}

\subsection{Deneysel ve Numerik Sonuçların Karşılaş̧tırılması (D1-N1, D2-N2, D3-N3)}

Yapılan deneysel ve numerik çalışmalar sonucunda TS 9967'ye BPEK-2018'e uygun olan (D1-N1) ve olmayan (D2-N2) aşık numunelerine ait yük ve deplasman grafikleri Şekil 12'de karşılaştırılmıştır. Deneysel çalışmada D1 numunesi D2'ye benzer şekilde kesme hasarına uğrayarak kapasiteye ulaşmış ancak \%10 daha fazla yük taşıdı̆̆ gözlenmiştir. Ayrıca D2 numunesinde kesme hasarı inceltilmiş bölge dışında gerçekleşirken, D1 numunesinde hasar inceltilmiş bölgede meydana gelmiştir. Yapılan karşılaştırmada numerik çalışmaların deney sonuçları ile örtüştüğü görülmektedir (Şekil 12).

Şekil 13'de D1 ve D2 deney numuneleri ile N1 ve N2 numerik modellerin yükleme sonunda oluşan hasarları gösterilmiştir. Hem numerik model hem de deneysel çalışma için gösterilen hasarlar deney sonrası elde edilmiştir. ABAQUS'de çatlak mekanizması birçok araştırmacı tarafından SDEG (rijitlik kaybı) kullanılarak gösterilmiştir [105-107]. Burada 1 değeri tamamen hasarlı elemanı temsil ederken 0 değeri hasarsız elemanı temsil eder. Hem numerik modelde hem de deneyde görüldüğü üzere TS 9967'ye ve BPEK-2018'e uygun olmayan numunelerde uç bölgedeki hasara ilaveten faydalı yükseklik (d) kadar içeride 45 derecelik kesme hasarı (D2-N2) oluşmaktadır. Ayrıca Şekil 12'de yapılan karşılaştırmadan da görüldüğg̈ üzere D1-N1 numunesinde fazladan kullanılan bir adet askı donatısının $\left(A_{v}\right)$ hasarı sınırlandırdığı anlaşılmaktadır. 


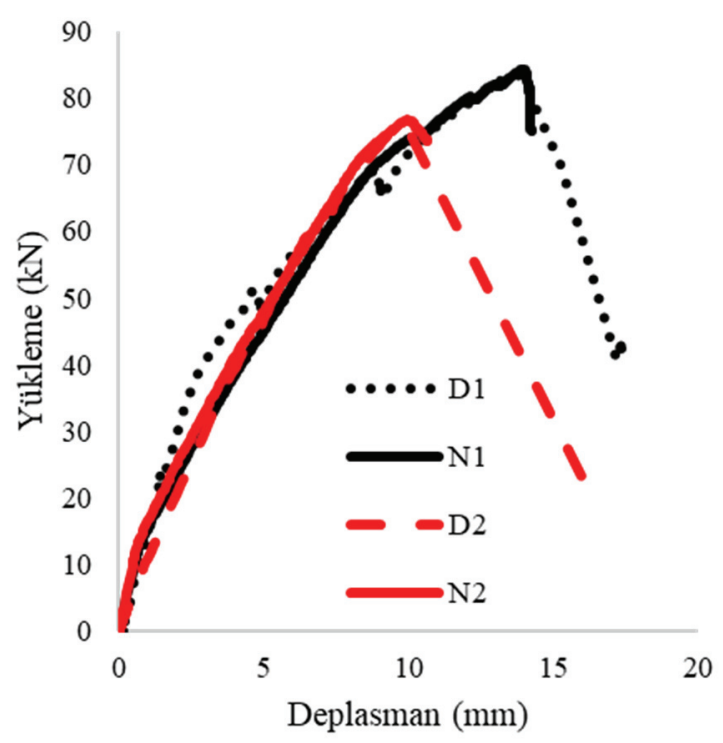

Şekil 12 - D1/N1 ve D2/N2 numunelerin deneysel ve numerik karşıllaştırılması
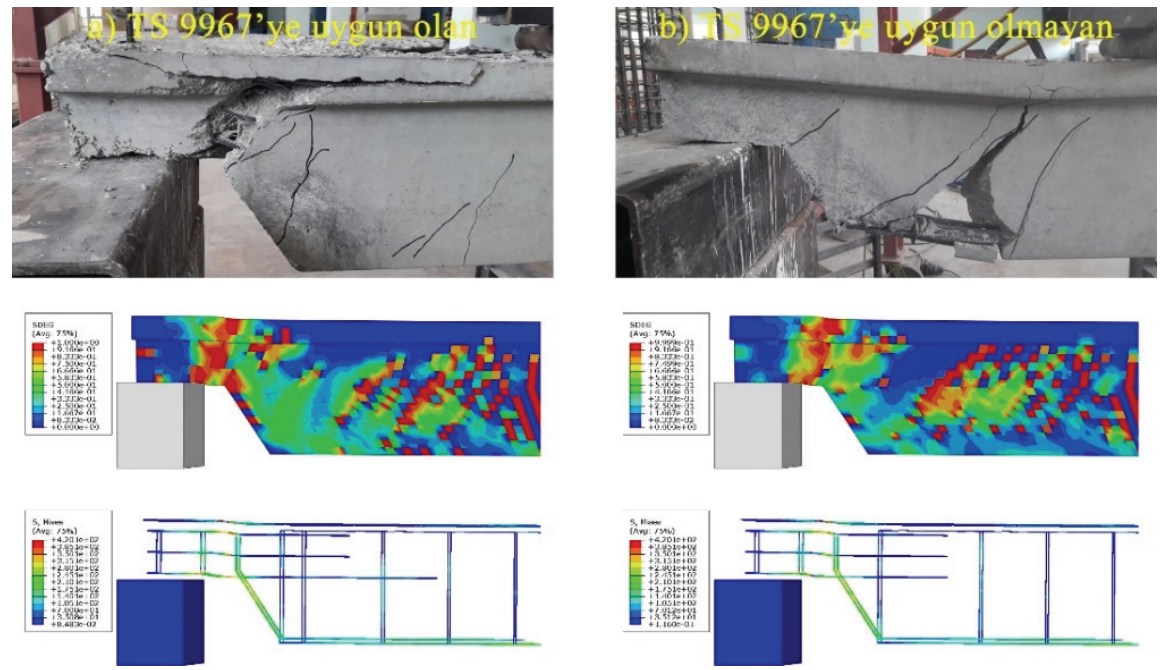

a) D1-N1 numunesi

b) D2-N2 numunesi

Şekil 13 - Standartlara a) uygun olan b) uygun olmayan numunelerde oluşan hasarlar

Deneysel çalışmada (D3) $\pm 45^{\circ}$ elyaf konfigürasyonunda tabakal1 $400 \mathrm{gr} / \mathrm{m}^{2}$ karbon kumaş kullanılmıştır. CFRP uygulamalar için F-1564 reçine ve F-3486-3487 sertleştirici kullanılmıştır. Deneysel çalışmada CFRP uygulamasının kirişin enerji tüketme kapasitesini artırdığg ve sünek davranışın gelişimine yol açtığg görülmüştür. Şekil 14'de Gemi ve diğg. [79] tarafından yapılan D3 numunesinin yük-deplasman sonuçları, numerik model ile elde edilen 
İnceltilmiş Uçlu Önüretimli Aşık Kirişlerinin Yük Taşıma Kapasitelerinin Deneysel ve ...

sonuçlarla karşılaştırılmıştır. Numerik model N3 de deney numunesi gibi sünek davranış sergilemiştir. N3'den elde edilen maksimum taşıma kuvveti $(120 \mathrm{kN})$ deneyde görülen maksimum yük taşıma kapasitesinden $(115 \mathrm{kN}) \% 4$ daha fazladır. Deneysel sonuçlar numerik model ile başarılı bir şekilde örtüşmüştür.

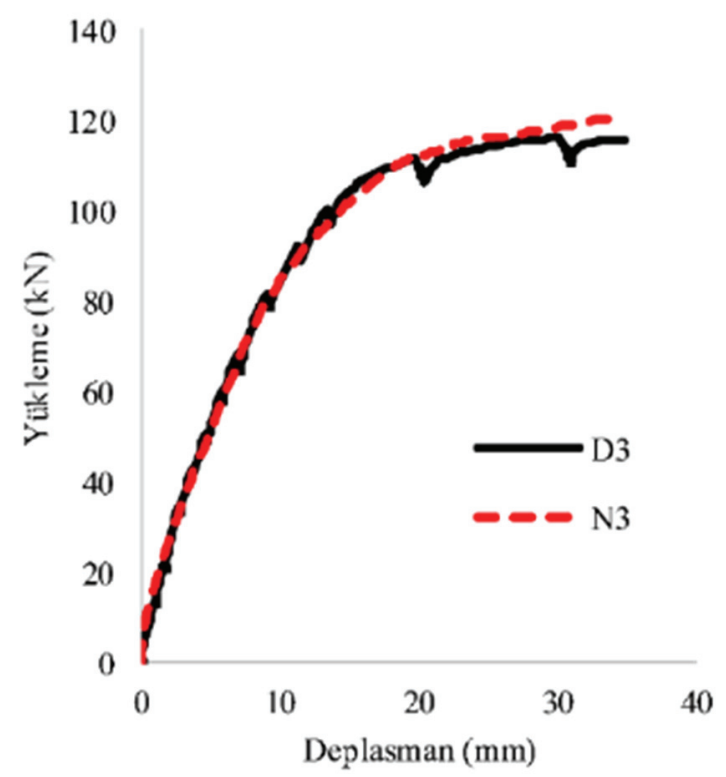

Şekil 14 - D3 ve N3 numunelerinin karşılaştırılması
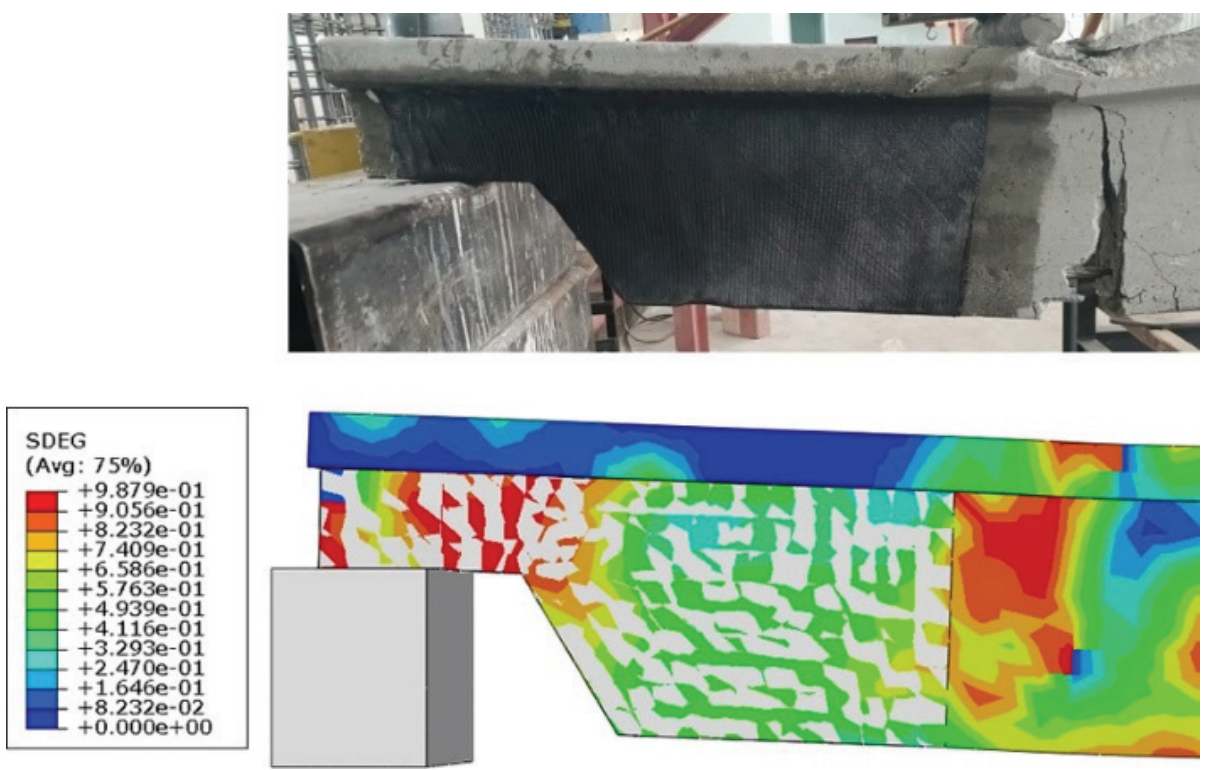

Şekil 15 - Güçlendirilmiş (D3) aşık modelinin numerik doğrulanması (N3) 
Şekil 15'de CFRP sargilı deneysel numunede oluşan hasarlar ve N3 numerik modelde elde edilen hasar bölgeleri gösterilmiştir. N3'de oluşan beton hasar bölgesindeki gerilme dağılımı CFRP'nin sargı etkisiyle uç bölgedeki kesme davranışını eğilme davranışına doğru yönelttiği görülmüş̧ür. Bu durum N3'de inceltilmiş uç bölgesinde gerilme yoğunluğu olmasına rağmen CFRP sargılama ile giderildiği anlaşılmıştır. Bu sayede kirişin kesme kapasitesi artarak CFRP sargının bittiği yerden başlayan çekme çatlakları sonucu sünek davranışın geliştiği görülmüştür. Ayrıca sonuç hasarının hem numerik modelde hem deneysel çalışmada aynı bölgede gerçekleştiği görülmüștür.

\subsection{Beton Basınç Dayanımı Değiş̧iminin Numerik Olarak Karşılaştııılması (N2-N4-N5)}

Deneysel çalışmada (D2) beton sınıfı C30 olarak dikkate alınmış ve buna göre numerik modelleme (N2) doğrulaması gerçekleştirilmişti. Burada beton sınıfı sırasıyla C20 (N4) ve C40 (N5) düşünülerek numerik analizler gerçekleştirilmiştir. N2, N4 ve N5 modellerin karşılaştırması Şekil 16'da gösterilmiştir. Numerik analizde N2 kendisi ile yalnızca beton sınıfı farklı olan N4 ve N5 ile karşılaştırıldığında, beton dayanımı $30 \mathrm{MPa}$ 'dan $40 \mathrm{MPa}$ 'ya çıktığında kesme kapasitesi \%21 artarken, beton dayanımı $30 \mathrm{MPa}$ 'dan $20 \mathrm{MPa}$ 'ya indiğinde kapasitenin \%10 azaldı̆̆ görülmektedir. Buradan beton sınıfının daha da artırılması durumunda betonun ezilmesinin gecikerek sünek davranışa yöneleceği anlaşılmaktadır. Ancak beton sınıfının çok yüksek seçilmesinin de ekonomik olmayacağı açıktır. Bu durum da uygulamada yaygın olarak kullanılan $40 \mathrm{MPa}$ dayanıma sahip beton sinıfinın yeterince uygun olduğu anlaşılmaktadır. Deneysel çalışmada yük transfer durumu dikkate alınarak ortalama beton dayanımı $30 \mathrm{MPa}$ olarak seçilmiştir. Ayrıca imalat hatalarından dolayı beton dayanımının yerinde $20 \mathrm{MPa}$ olması durumu ile halen firmaların tercih ettiği fabrika standardı olan $40 \mathrm{MPa}$ beton sınıfı düşünülerek de analizler gerçekleştirilmiştir.

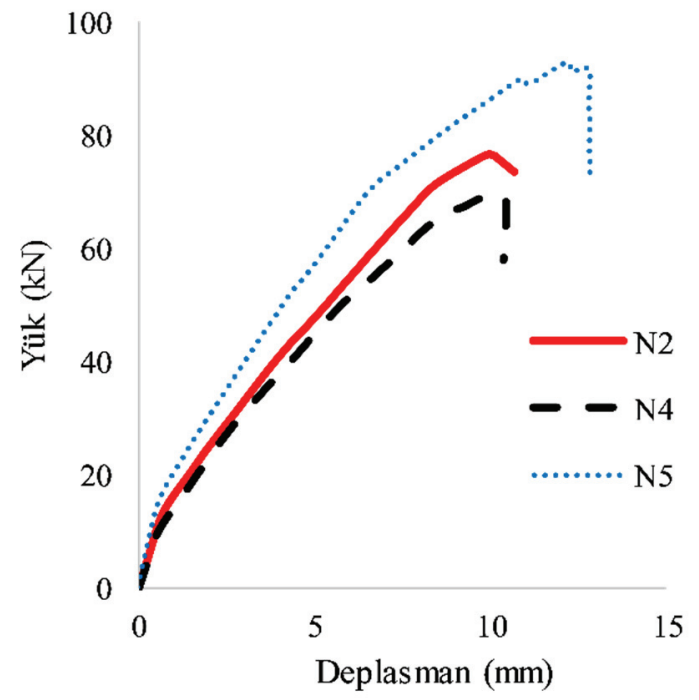

Şekil 16 - N2/N4/N5 modellerin karşılaştırması 


\subsection{Donatı Akma Dayanımı Değişiminin Numerik Olarak Karşılaştırılması (N2-N6)}

TS 9967 ve BPEK, 2018'e uygun olmayan deneysel çalışmanın (D2) doğrulamas1 (N2) yapıldıktan sonra yalnızca donatı dayanımının değişimi ile karşılaştırma yapılmıştır. Şekil 17'de donatı kalitesinin değişimine yönelik karşılaştırma gösterilmiştir. Burada çekme donatı akma dayanımı $420 \mathrm{MPa}$ olan N2 numunesi, akma dayanımı $500 \mathrm{MPa}$ olan N6 numunesi ile karşılaştırılmıştır. Diğer tüm parametrik özellikleri aynı olan N2 ve N6 karşılaştırıldığında yalnızca donatı kalitesinin yüksek olduğu N6 numunesinde kesme kapasitesinin N2'ye göre \%8 artış sağladığı görülmüştür. Bu durum da uygulamada standart aşıklarda kullanılan donatı kalitesinin değiştirilmesinin çok da etkili olmadığı söylenebilir.

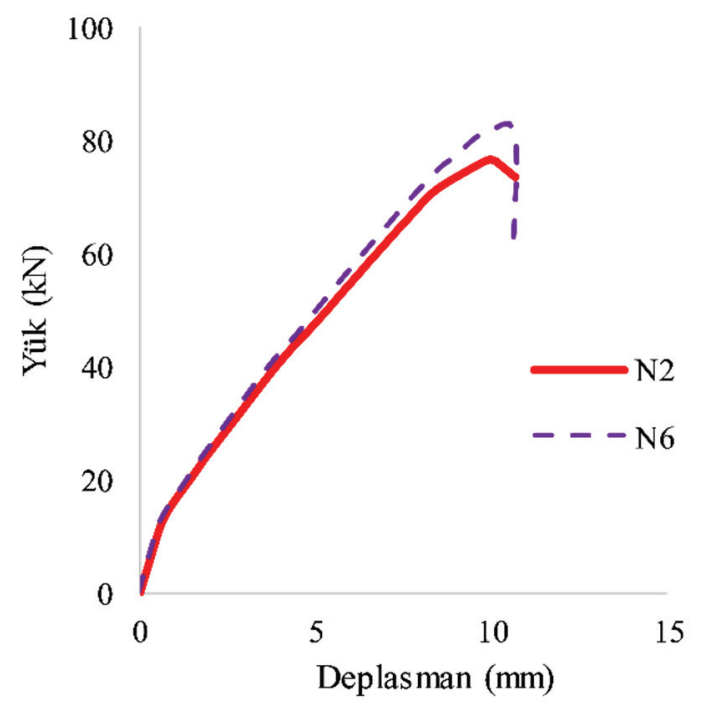

Şekil 17 - N2 ve N6 modellerin karşılaştırması

\section{4. Öngerme Kuvveti Değişiminin Numerik Olarak Karşılaştırılıması (N2-N7-N8)}

Uygulamada genellikle aşık elemanların beton sınıfı, çelik sınıfı ve ön germe nihai halat kapasitesi $\left(\% \mathrm{f}_{\text {pu }}\right)$ değişmemektedir. Özellikle ön germe halatları azami yük taşıyacak şekilde hesaplanmakta ve ekonomik olması için \%65-70 $\mathrm{f}_{\mathrm{pu}}$ oranında gerilmektedir. TS 3323 [37] ve AASHTO [108] rötre ve sünmeden kaynaklanan kayılardan önce geçici emniyet gerilmelerinin gerilmenin yapılacağı andaki dayanım baz alınmak kaydıyla basınç gerilmesi olarak $0.6 f_{c}$, servis yükleri altında kayıplardan sonra emniyet gerilmeleri 28 günlük basınç dayanımı baz alınmak kaydıyla $0.4 \mathrm{f}_{\mathrm{c}}$ olarak kabul edilmektedir. Benzer şekilde çekme gerilmesi içinde $0.6 \sqrt{ } \mathrm{f}_{\mathrm{c}}$ baz alınmaktadır.

Aşıklarda kullanılan ve genellikle standart olan 1/2" (12.7 mm çapında) bir halatın akma ve kopma gerilmelerinin $1250 \mathrm{MPa}$ ve $1450 \mathrm{MPa}$ olduğu düşünüldüğü zaman bu halata uygulanabilecek olan teorik kuvvetin maksimum değeri akma anında $160 \mathrm{kN}$ kopma anında ise $184 \mathrm{kN}$ 'dir. Aşıklarda ters sehimi sınırlandırmak ve yukarıda belirtilen gerilme 
seviyelerinde kalmak için uygulamada öngerme kuvvetleri 100 ila $160 \mathrm{KN}$ arasında kalmaktadır. Bu nedenle numerik çalışmada uygulamadaki mevcut kullanım dışındaki halleri parametre olarak dikkate alınmış ve uygulamada genellikle kabul gören kullanım değerlerine göre analiz edilmiştir.

Numerik çalışmada uygulamadaki mevcut kullanım dışındaki halleri parametre olarak dikkate alınmış ve uygulamada kabul gören kullanım değerleri analiz edilmiştir. Tasarımda bu kapasite değişmiyor olsa da bazı durumlarda kesitlerde ön germe kayıpları yaşandığı ya da fazla öngerme verilebileceği durumlardaki değiş̧im gözlenmek istendiğinden dikkate alınmıştır.

Analiz sonuçların Şekil 18'de karşılaşıırma olarak verilmiştir. Burada N2 ile tüm özellikleri aynı olan yalnızca öngerme kapasitesi artırılan N7 ve azaltılan N8 numunelerin kapasitesinde belirgin bir değişiklik gözlenmemiştir. Kapasitelerde bu oranda farklılığın oluşmasının temel sebebi aşığın eğilme davranışını göstermeden kesmeden dolayı göçmesidir. $\mathrm{Bu}$ durumda öngerme kapasite değişiminin kesme kapasitesine ciddi bir katkı sağlamadığı görülmüştür. $\mathrm{Bu}$ durum da uygulamada yaygın olarak kullanılan ön germe halatları için dikkate alınan kapasite değerlerinin uygun olduğu söylenebilir.

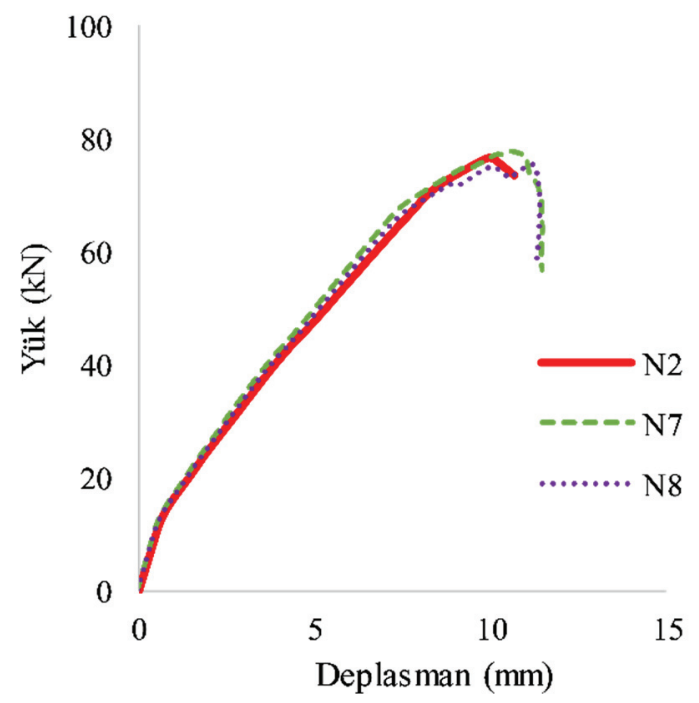

Şekil 18 - N2/N7/N8 modellerin karşılaştırması

\subsection{CFRP Sargılamanın Değişiminin Numerik Olarak Karşılaştırılması ve Güçlendirme Uygulamaları İçin Çözüm Önerileri (D2-N9-N10-N11)}

Deneysel kısımda test edilen ve tam sargılı olarak (numuneyi U şeklinde saran) CFRP uygulaması gerçekleştirilen D3 numunesinin kesme kapasitesini önemli oranda artırdığ görülmüştü. Laboratuvar şartlarında yapılan bu uygulamanın aslında uygulamada çatı 


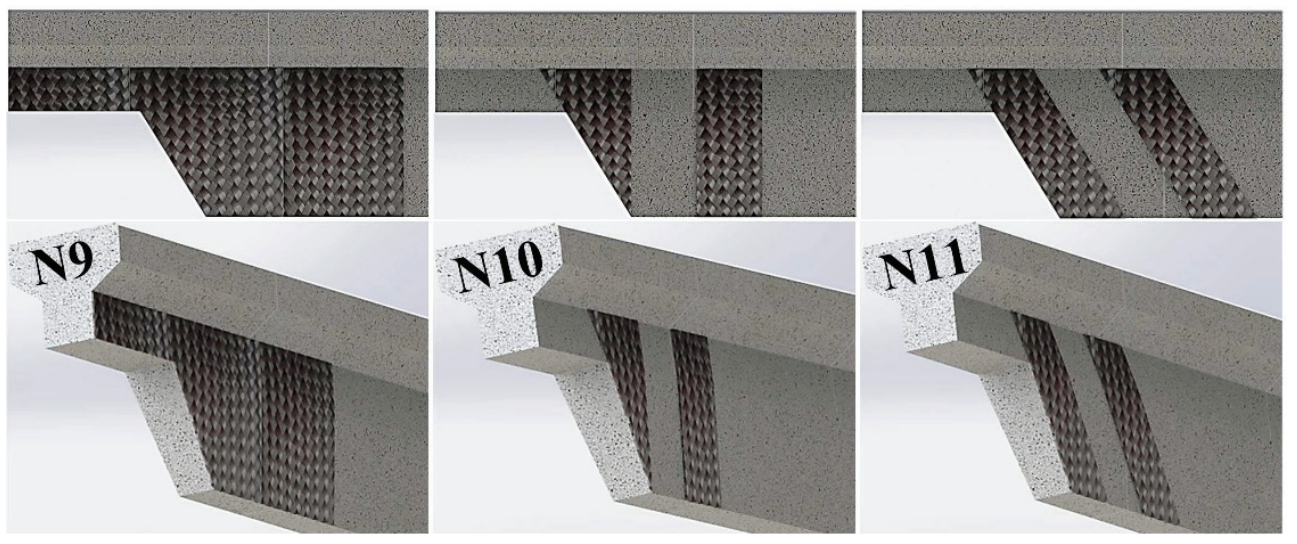

Şekil 19 - Önerilen güçlendirilmiş yeni numerik modeller

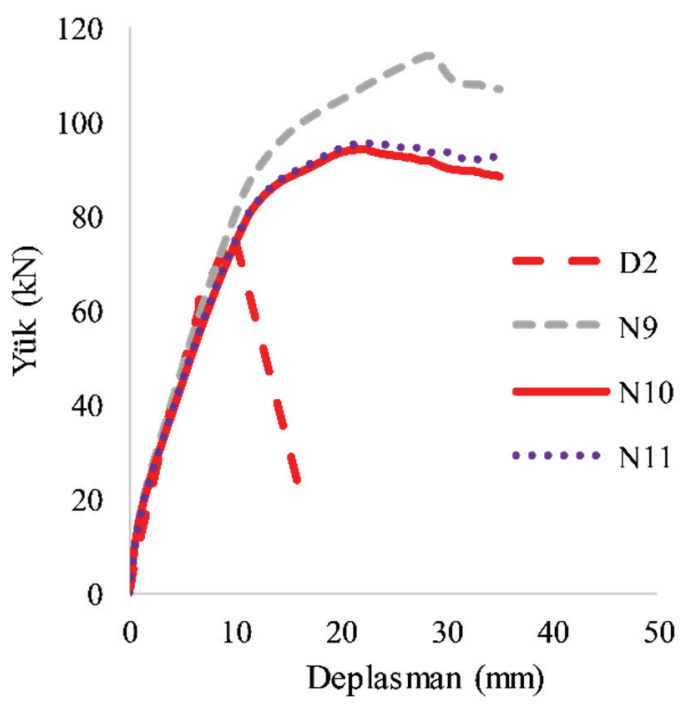

Şekil 20 - D2/N9/N10/N11 modellerin karşılaştırması

kaplamasının ve aşıların de-montajına gerek duyulacağı için çok pratik olmayacağ düşüncesiyle Şekil 19'da verilen alternatif CFRP güçlendirme modelleri için bir dizi parametrik çalışma yapılmış̧ır. Burada hem pratik uygulanabilir hem de daha az karbon kumaş kullanarak kesme kapasitesini artırmak amaçlanmıştır. Şekil 20'de yapılan karşılaştırmalarda CFRP'nin farklı yerleşim durumunda kesme kapasitesini D2'ye göre artırdığı ve uygulamada tercih edilebileceği görülmektedir. Bunun için ilk olarak N9 numunesinde kiriş yan yüzeylerine tamamen CFRP sargılaması uygulanmıştır. İkinci olarak N10 numunesinde N9 ile aynı konfigürasyonda parçalı şerit şeklinde CFRP uygulaması 
yapılmıştır. Son olarak N11 numunesinde aynı karbon kumaş yaklaşık $45^{\circ}$ 'lik açı ile uygulanarak analizler gerçekleştirilmiştir. Yapılan numerik analizde N9 numunesinin kapasitesi N10 ve N11'e göre belirgin artış sağlamıştır. N9 numunesi sargı etkisiyle 113.8 $\mathrm{kN}$ yük ve $28.5 \mathrm{~mm}$ deplasman seviyesinde kesmeli eğilme hasarına uğramıştır. CFRP uygulaması kapasitede referans numuneye göre \%50'lik artış sağlamıştır. Aynı zamanda davranış gevrekten sünek davranışa yönelmiştir. N10 ve N11 numunelerinde ise yaklaşık 95 $\mathrm{kN}$ yük ve $22 \mathrm{~mm}$ deplasman seviyesinde sargı etkisinin azalmasıyla kiriş göçme konumuna ulaşmıştır. CFRP uygulamalarında beton ile mükemmel yapışma kabul edildiğinden ilave ankraj detayı dikkate alınmamıştır. D3 numunesinde elde edilen gözlemler tam sarg1 (U şeklinde) neticesinde beton ile CFRP arasında iyi bir ara yüzeyin oluştuğu görüldügünden bu modellerde ankraj uygulaması da düşünülmemiştir. N9 numunesi deneysel olarak doğrulanan N3 numunesi ile karşılaştırıldığında çekme bölgesine CFRP uygulaması yapılmadığı halde yük taşıma kapasitelerine ve deplasman değerlerine yaklaşmıştır. Bu değerler sırasıyla N9 için $113.8 \mathrm{kN}$ ve $28.5 \mathrm{~mm}$ iken N3 için $120.6 \mathrm{kN}$ ve $34.3 \mathrm{~mm}$ 'dir. Dolayısıyla bu durum önerilen yeni CFRP yerleşiminin uygulanabileceğini göstermektedir. N10 ve N11 numunelerinin düşük çıkması uygulama yüzey alanının azalmasından kaynaklandığı söylenebilir. Bu numuneler için uygulamada ankraja ihtiyaç duyulabilir [109]. Bunun için N10 ve N11 numunelerinin uygulanması durumunda ankraj görevi yatay doğrultuda CFRP uygulaması ya da mekanik ankraj uygulaması yapılması önerilmektedir [110-118].

\subsection{Donatı Detayı Değişiminin Numerik Olarak Karşılaş̧ırılması ve Yeni Yapılacak Aşıklar İçin Çözüm Önerileri (N1-N12-N13)}

Yapılan kapsamlı numerik analiz çalışmaları sonucunda uygulamada aşıkların üretim aşamasında dikkate alınması için bir takım çözüm önerileri sunulmuştur. Bunun için standartlarda verilen mevcut donatı düzenini geliştirmek için iki farklı model önerilmektedir. $\mathrm{Bu}$ modeller geliştirilirken Şekil 13'de verilen donatı gerilmeleri göz önünde bulundurulmuştur. Şekil 13'de görüldüğü üzere $A_{v}$ etriyesi ile $A^{\prime}{ }_{s h}$ donatısı arasında kalan donatılarda yoğun gerilmeler oluşmaktadır. En uç bölgede kalan $A_{v}$ etriyesinde ise herhangi bir gerilme gözlenmemiştir. Bu etriye daha çok montaj kaygısı nedeniyle kullanılmamaktır. $\mathrm{Bu}$ çalışmada bu etriyenin Şekil 21'deki gibi $\mathrm{A}_{\mathrm{v}}$ ile $\mathrm{A}_{\text {sh }}$ donatısı arasına yerleştirilmesi önerilmiştir. Montaj için ise üstteki ve alttaki donatılar L şeklinde kanca yapılarak son nokta teşkil edilebilir. Referans numunesi olan N1 numunesi $84.2 \mathrm{kN}$ yükte ve $14.8 \mathrm{~mm}$ deplasmanda maksimum yüke ulaşırken önerilen N12 numunesi $103.9 \mathrm{kN}$ yükte ve $19.2 \mathrm{~mm}$ deplasman değerinde maksimum yüke ulaşmıştır. Bu da yük kapasitesinde \%24'lük ve deplasman kapasitesinde \%30'luk artışa tekabül etmektedir. Önerilen ikinci alternatif ise yük ve deplasman değerinde değişiklik olmadan gereksiz donatıyı azaltmaya yöneliktir. Bu öneride $A_{s}$ ve $A_{h}$ donatılarının kenetlenme boyu üzerinde birtakım modeller oluşturulmuştur. Şekil 13'de görüldügüü üzere bu donatılar üzerinde gerilmenin oldukça düşük olduğu bölgeler vardır. $\mathrm{Bu}$ durum göz önüne alınarak deneme-yanılma yöntemiyle yük ve deplasman değerinde değişiklik olmayacak şekilde bir dizi numerik analizler gerçekleştirilerek optimum kenetlenme boyu elde edilmeye çalışılmıştır. Optimum sonuca $100 \mathrm{~mm}$ kenetlenme boyu ile edilmiştir. Şekil 21'de elde edilen yük-deplasman değerleri karşıllaştırılmıştır. Şekil 21 b'de görüldüğü üzere maksimum yük ve maksimum yüke tekabül eden deplasman değerleri arasındaki fark belirgin derecede değildir. Şekil 22'de N12 ve N13 numunelerinin donatı detayları gösterilmiştir. 
İnceltilmiş Uçlu Önüretimli Aşık Kirişlerinin Yük Taşıma Kapasitelerinin Deneysel ve ...
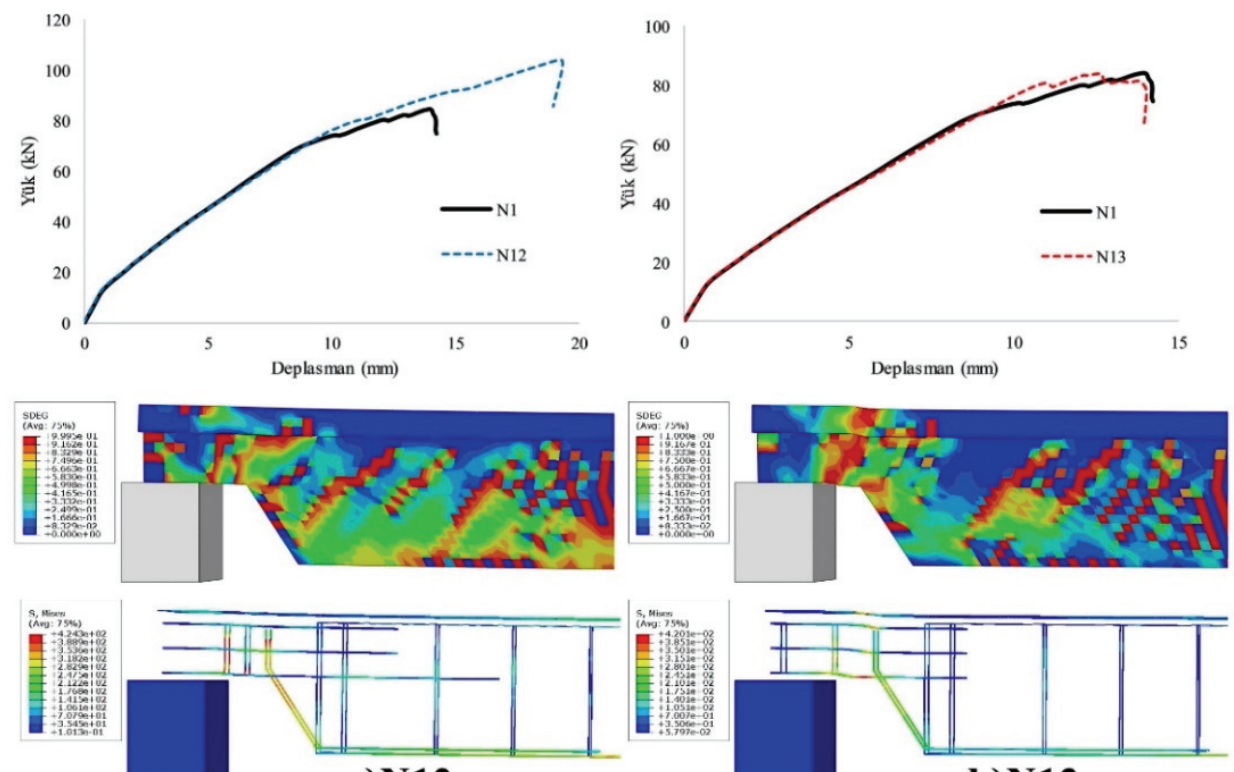

a)N12

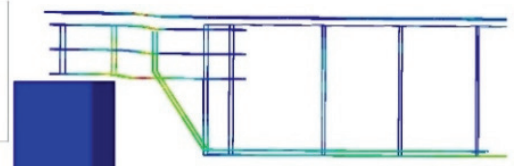

b)N13

Şekil 21 - Önerilen donatı detayları
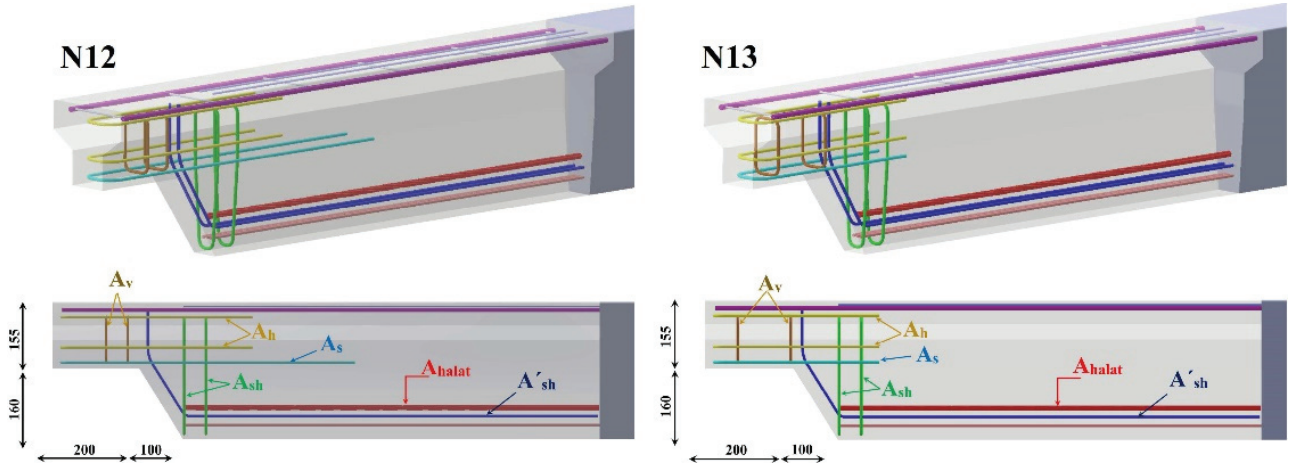

Şekil 22 - Numerik modeller sonucunda önerilen yeni donatı detayı

\section{TARTIŞMA, SONUÇLAR VE ÇÖZÜM ÖNERILERİ}

Bu çalışmada düşey yük etkisi altında deneysel sonuçları elde edilen inceltilmiş uçlu aşık kirişlerinin üç boyutlu sonlu eleman modelinde numerik karşılaştırılması yapılmıştır. Daha sonra farklı parametreler kullanılarak numerik çalışma geliştirilmiştir. Numerik hesaplamalar sonucunda aşağıdaki sonuçlara ulaşılmıştır; 
- Önerilen sonlu eleman modelleme yaklaşımı, düsşey yükler etkisi altında olan inceltilmiş uçlu aşık kirişlerin davranışlarını gözlemlemek için kullanılabilir durumdadır.

- Modellenen her bir malzemenin davranışı tanımlanan ağ boyutlarına bağlıdır. Burada tanımlanan ağ boyutlarının uygun olduğu görülmektedir.

- Sonlu eleman analizi gerçekleştirilen kirişlerde beton modeline uygun parametrelerin seçilmesi davranışı etkileyeceğinden dikkat edilmelidir.

- Sonlu elaman analizleri ile yük-deplasman eğrileri, beton, çelik, diğer malzemelerin gerilme-ş̧ekil değiştirme ilişkileri ve çatlak oluşum yerleri gösterilebilir olduğundan maliyetli deneysel çalışmalara alternatif olarak kullanılabilir.

- Yapılan saha çalışmalarında özellikle hasar gören aşıkların bir kısmında aşık uç donatı düzenlerinin yetersiz olduğu ve beton basınç dayanımlarının projede öngörülen değerin oldukça altında kaldığı görülmüsstür. Bu nedenle çalışmada; aşıkların modellenmesinde özellikle aşıkların uç donatılarında bazı değişikliklere de gidilmiş̧ir.

- Beton dayanımının düşürülmesi (N4) kapasiteyi düşürmekte ve yükseltilmesi (N5) de kapasiteyi artırmakta olduğu numerik model üzerinden rahatlıkla görülebilmektedir. Benzer durum donatı kalitesi içinde söylenebilir.

- Ön germe halat kapasitesinin artırılması (N7'den N8'e geçilmesi), kiriş kesme kapasitesi ve deplasman yapma kabiliyetini yok denecek kadar az değiştirmiştir (yaklaşı \%1).

- Yapılan numerik modelleme sonucunda inceltilmiş mevcut aşıklar için uç bölgesinde oluşan kesme hasarını önlemeye yönelik CFRP sargılanmasının oldukça başarılı olduğu söylenebilir.

- Çalışmada test edilen D3 numunesi sadece deneysel çalışma için kurgulanmıştır. Uygulamada özellikle mesnet bölgelerinde aşığın kaldırılmadan uygulanması mümkün olmayacaktır. Bunun için numerik analiz kısmında aşıkların yerinden kaldırılmaması adına farklı tip güçlendirme modelleri numerik olarak analiz edilmiş ve kapasiteyi artırıcı sonuçlara ulaşılmıştır. Bu tip güçlendirme yöntemlerinin uygulamada kullanılabileceği önerilmektedir.

- Önerilen CFRP uygulaması yük taşıma kapasitesini \%50 artırmışır. Aynı zamanda aşık uçlarındaki gevrek kesme kırılması engellenmiş açıklık donatısının akmasıyla sünek davranış ortaya çıkmıştır.

- Uçta kalan $A_{v}$ etriyesi gerilmelerin en yoğun olduğu yere taşınması önerilerek kapasitede \%24'lük bir artış sağlanmıştır.

- Kenetlenme boyunun 100 mm'e düşürülerek kapasitede bir değişiklik olmadan donatı miktarının azaltılması önerilmiştir.

Uygulamada kar yükünün çatının bazı bölgelerinde birikmesi, uzun süreli kalması, karın birim ağırlığının zamanla artması, kar ile beraber rüzgârında etki etmesi gibi nedenlerden dolayı yükler tasarımcının hesap değerlerinin oldukça üzerine çıkabilmektedir. Bu durumda 
da aşık uçlarında kesme kırılmaları meydana gelmektedir. Bu çalışma ışığında özellikle fazla yüklü aşıklarda aşık boyutlarında mimari ve üretim sebeplerinden dolayı bir değişiklik yapılamayacaksa CFRP uygulaması ile aşığın yük taşıma kapasitesinde ve sünekliğinde önemli iyileşmelerin olacağı görülmüşstür.

Burada CFRP uygulamasının ekonomik bir çözüm olup olmayacağını tartışmak gerekmektedir. Sanayi yapılarında aşık sistemlerinin sökülmesi için ilk olarak mevcut çatı kaplamasının sökülmesi, daha sonra aşığın tepe kirişle olan ve pimler yardımıyla sağlanmış birleşim bölgelerinden alınması ve yeni aşı̆̆ın eğer zarar görmediyse mevcut pimlere tekrar oturtularak eski çatı kaplamasıyla aşıkların kapatılması gerekmektedir. Bu işlemlerin mevcut kaplamaya, pimlere ve çatı kirişine zarar verme ihtimali düşünülmelidir. Bu imalat yerine mevcut aşık korunarak kaplama açılmadan fabrika içinde yapılabilecek CFRP takviyesi aşık performansını olumlu etkileyeceği için tercih sebebi olabilir.

Bu çalışma neticesinde yapılacak gelecek çalışmalarda, inceltilmiş uç bölgesinin farklı lifli polimer malzemeler ile sarılması ve malzemelerin birden çok katmanlı uygulanması durumunda kesme kapasitesinin değişimi araştırılabilir.

\section{Teşekkür}

Yazarlar numunelerin üretilmesini sağlayan Yardımcı Prefabrik Yapı Elemanları A.Ş.’ye teşekkür ederler.

\section{Kaynaklar}

[1] Günerman, H., Prefabrike Bina Sistemleri. Prefabrike İnşaat Teknolojileri Sempozyumu, 23-6, 1997.

[2] Şenel, Ş.M., Palanci, M., Kalkan, A., Yılmaz, Y., Mevcut Prefabrik Binaların Mafsallı Birleşimlerinin Kesme ve Devrilme Güvenliğinin Araştırılması, Teknik Dergi, 24, 119 , 2013.

[3] Taştekin, M.S., Sanayi yapılarında prefabrik betonarme ve çelik konstrüksiyon uygulamalarının ekonomik yönden karşılaştırılması, Yüksek Lisans Tezi, Selçuk Üniversitesi Fen Bilimleri Enstitüsü, 2006.

[4] Reynolds, G., The strength of half-joints in reinforced concrete beams, Cement and Concrete Association, 1969.

[5] Mattock, A.H., Chan, T.C., Design and behavior of dapped-end beams, PCI journal, 24, 28-45, 1979.

[6] Mattock, A., Theryo, T., Strength of Prestressed concrete members with dapped endsreply, Journal Prestressed Concrete Institute, 32, 120-1, 1987.

[7] Solanki, H., Strength of Prestressed Concrete Members with Dapped Ends-Comment, Journal Prestressed Concrete Instute, 32, 119-20, 1987.

[8] Shakir, Q.M., Reinforced Concrete Dapped End Beams-State of the Art, International Journal of Applied Science, 1, 2, 44-57, 2018. 
[9] Ahmad, S., Elahi, A., Junaid, H.M.F., Ahsan, Z., Evaluation of the shear strength of dapped ended beam, Life Science Journal, 10, 1038-44, 2013.

[10] Yazman, Ş., Aksoylu, C., Özkılıç, Y., Gemi, L., Arslan, M.H., Sanayi Yapılarında Kullanılan Betonarme Prefabrike Öngerilmeli Aşıkların Kesme ve Eğilme Kapasitelerini Artırmaya Yönelik CFRP Uygulaması, International Science and Academic Congress (INSAC'19), 292-8, 2019.

[11] Aksoylu, C., Yazman, Ş., Özkılıç, Y., Gemi, L., Arslan, M.H., İnceltilmiş Uçlu Betonarme Prefabrik Aşıların Kesme Kapasitelerinin CFRP uygulaması ile Artır1lmas1. International Science and Academic Congress(INSAC'19), 285-91, 2019.

[12] Özkılıç, Y., Aksoylu, C., Yazman, Ş., Gemi, L., Arslan, M.H., Prefabrike İnceltilmiş Aşık Uçlarının Deneysel ve Numerik Sonlu Eleman Analizlerinin Karşıllaştırılması. International Science and Academic Congress(INSAC'19), 299-307, 2019.

[13] Hwang, S-J., Lee, H-J., Strength prediction for discontinuity regions by softened strutand-tie model, Journal of Structural Engineering, 128, 1519-26, 2002.

[14] Aksoylu, C., Özkılıç, Y.O., Yazman, Ş., Gemi, L., Arslan, M.H., The Numerical Study of The Effects of Steel Reinforcement Ratio to Behavior of Prefabricated Purlins, 2nd International Congress on Engineering and Architecture (ENAR), 1759-65, 2019.

[15] Aswin, M., Mohammed, B.S., Liew, M., Imam, Z.S., Root cause of reinforced concrete dapped-end beams failure, Abu Dhabi University, 2015.

[16] Aswin, M, Mohammed BS, Liew M, Syed ZI. Shear failure of RC dapped-end beams. Advances in Materials science and engineering, 11, 2015.

[17] Aswin, M., Syed, Z.I., Wee, T., Liew, M.S., Prediction of failure loads of RC dappedend beams, Applied Mechanics and Materials, Trans Tech Publ, 567, 463-8, 2014.

[18] Atta, A., Taman, M., Innovative method for strengthening dapped-end beams using an external prestressing technique, Materials and Structures, 49, 3005-19, 2016.

[19] Hussain, H.N., Shakir, Q.M., Experimental Study of the Behavior of Reinforced Concrete Beams with Composite Dapped End under Effect of Static and Repeated Loads, International Journal of Applied Science, 2, 43-55, 2019.

[20] Kotsovos, G.M., Cotsovos, D.M., Half-joint beam design based on the CFP theory, Proceedings of the Institution of Civil Engineers-Structures and Buildings, 768-777, 2019.

[21] Lin, I-J., Hwang, S-J., Lu, W-Y., Tsai, J-T., Shear strength of reinforced concrete dapped-end beams, Structural Engineering and Mechanics, 16, 275-94, 2003.

[22] Lu, W.Y., Lin, I.J., Hwang, S.J., Lin, Y.H., Shear strength of high-strength concrete dapped-end beams, Journal of the Chinese Institute of Engineers, 26, 671-80, 2003.

[23] Lu, W-Y., Lin, I-J., Yu, H-W., Behaviour of reinforced concrete dapped-end beams, Magazine of Concrete Research, 64, 793-805, 2012. 
[24] Mata-Falcón, J., Pallarés, L., Miguel, P.F., Proposal and experimental validation of simplified strut-and-tie models on dapped-end beams, Engineering Structures, 183, 594-609, 2019.

[25] Moreno-Martínez, J.Y., Meli, R., Experimental study on the structural behavior of concrete dapped-end beams, Engineering Structures, 75, 152-63, 2014.

[26] Nagrodzka-Godycka, K., Piotrkowski, P., Experimental Study of Dapped-End Beams Subjected to Inclined Load, ACI Structural Journal, 109, 11-20, 2012.

[27] Peng, T., Influence of detailing on response of dapped-end beams [Ms Thesis], McGill University Montréal, Canada, 2009.

[28] Rymeš, J., Štemberk, P., Kohoutkova, A., Experimental Analysis of Strengthening of Dapped-End Beams, Key Engineering Materials: Trans Tech Publ, 241-6, 2017.

[29] Shakir, Q.M., Alliwe, R., Behavior of Self-Compacting Reinforced Concrete Dapped End Beams, International Journal of Applied Science, 2, 43-55, 2019.

[30] Syed, Z.I., Sami, E., Ahmed, M.O., Modelling of Dapped-End Beams under Dynamic Loading, Abu Dhabi University, 2017.

[31] Özkılıç, Y., Aksoylu, C., Yazman, Ş., Gemi, L., Arslan M.H., The Effects of Material Properties and Pretension to Behavior ofPrefabricated Purlins, 2nd International Congress on Engineering and Architecture (ENAR), 1754-8, 2019.

[32] Yazman, Ş., Aksoylu, C., Özkılıç, Y.O., Gemi, L., Arslan, M.H., Experimental and Numerical Investigation of Prefabricated Thinned Ended Purlins with and without CFRP Composites, 2nd International Congress on Engineering and Architecture (ENAR), 575-9, 2019.

[33] Yang, K-H., Ashour, A.F., Lee, J-K., Shear strength of reinforced concrete dapped-end beams using mechanism analysis, Magazine of Concrete Research, 63, 81-97, 2011.

[34] Aksoylu C, Özkılıç YO, Arslan MH. Damages on Prefabricated Concrete Dapped-End Purlins due to Snow Loads and a Novel Reinforcement Detail. Engineering Structures. $225,2020$.

[35] Handbook PD., Precast and prestressed concrete. Precast/Prestressed Concrete Institute, Chicago, IL, 1999.

[36] TS9967., Yapı Elemanları, Taşıyıcı Sistemler ve Binalar-Prefabrike Betonarme ve Öngerilmeli Betondan-Hesap Esasları ile İmalat ve Montaj Kuralları, Türk Standartları Enstitüsü, İstanbul, 1992.

[37] TS3233., Öngerilmeli Yapıların Hesap ve Yapım Kuralları, Türk Standartları Enstitüsü. 1-44, 1979.

[38] Barka, G., Ataköy, H., Yüksel, E., Beton Prefabrikasyon El Kitabı, Tasarım, Üretim ve Montaj Esasları, Türkiye Prefabrik Birliği, 2018.

[39] TBDY2019., Türkiye Bina Deprem Yönetmeliği, Deprem Etkisi Altında Binaların Tasarımı İçin Esaslar, Ankara. 
[40] Standard T., Eurocode 1-Actions on structures-Part 1-3, General actions-Snow loads (TS EN 1991-1-3), Institute of Turkish Standard (TSE), Ankara, Turkey. 2007.

[41] Chen, B.S., Hagenberger ,M.J., Breen, J.E., Evaluation of strut-and-tie modeling applied to dapped beam with opening, Structural Journal, 99, 445-50, 2002.

[42] Committee, A., Standardization IOf. Building code requirements for structural concrete (ACI 318-08) and commentary, American Concrete Institute, 2008.

[43] Gundogan, G., İnceltilmiş Uçlu Prefabrike Kiriş Birleşimlerinin Türk (TS9967) ve Amerikan (PCI) Yönetmelikleriyle Karşılaştırılması [Yüksek Lisans], Eskişehir Osmangazi Üniversitesi, Fen Bilimleri Enstiüsü, 2010.

[44] Enstitüsü TS., TS 500 Betonarme Yapıların Tasarım ve Yapım Kuralları, Ankara, Türkiye, 2000.

[45] Aksoylu, C., Kara, N., Strengthening of RC frames by using high strength diagonal precast panels, Journal of Building Engineering., 31, 101338, 2020.

[46] Aksoylu, C., Sezer, R., Investigation of precast new diagonal concrete panels in strengthened the infilled reinforced concrete frames, KSCE Journal of Civil Engineering, 22, 236-46, 2018.

[47] Aksoylu, C., Kara, N., Güçlendirme Tekniği Olarak Yeni Nesil Ön Üretimli Beton Panel Uygulamasının Araştırılması, Selçuk Üniversitesi Mühendislik, Bilim ve Teknoloji Dergisi, 7, 346-61, 2019.

[48] Madenci, E., Özkılıç, Y.O., Gemi, L., Experimental and theoretical investigation on flexure performance of pultruded GFRP composite beams with damage analyses, Composite Structures, 242, 112162, 2020.

[49] Özkılıç, Y.O., Madenci, E., Gemi, L., Tensile and Compressive Behaviors of the Pultruded GFRP Lamina, Turkish Journal of Engineering (TUJE), 4, 169-75, 2020.

[50] Ghatte, H.F., Comert, M., Demir, C., Akbaba, M., Ilki, A., Seismic Retrofit of FullScale Substandard Extended Rectangular RC Columns through CFRP Jacketing, Test Results and Design Recommendations, Journal of Composites for Construction, 23, $04018071,2019$.

[51] Cosgun, C., Cömert, M., Demir, C., İlki, A., Seismic Retrofit of Joints of a Full-Scale 3D Reinforced Concrete Frame with FRP Composites, Journal of Composites for Construction, 23, 04019004, 2019.

[52] Ates, A.O., Khoshkholghi, S., Tore, E., Marasli, M., Ilki, A., Sprayed Glass FiberReinforced Mortar with or without Basalt Textile Reinforcement for Jacketing of LowStrength Concrete Prisms, Journal of Composites for Construction, 23, 04019003, 2019.

[53] Köroğlu, M.A., Ceylan, M., Arslan, M.H., İlki, A., Estimation of flexural capacity of quadrilateral FRP-confined RC columns using combined artificial neural network, Engineering Structures, 42, 23-32, 2012. 
[54] Ilki, A., Bedirhanoglu, I., Kumbasar, N., Behavior of FRP-Retrofitted Joints Built with Plain Bars and Low-Strength Concrete, Journal of Composites for Construction, 15, 312-26, 2011.

[55] Ilki, A., Demir, C., Bedirhanoglu, I., Kumbasar, N., Seismic Retrofit of Brittle and Low Strength RC Columns Using Fiber Reinforced Polymer and Cementitious Composites, Advances in Structural Engineering, 12, 325-47, 2009.

[56] Arslan, M.H., Aksoylu, C., Gemi, L., Yazman, Ş., Özkılıç, Y.O., Effect of Circular Holes in Shear Region on the Behavior of CFRP Strengthened RC Beams, 4th Eurasian Conference on Civil and Environmental Engineering (ECOCEE), İstanbul, 860-5, 2019.

[57] Çetinkaya, N., Kaplan, H., Şenel, Ş.M., Betonarme Kirişlerin Lifli Polimer (FRP) Malzemeler Kullanılarak Onarım ve Güçlendirilmesi, Pamukkale Üniversitesi Mühendislik Bilimleri Dergisi, 10, 291-8, 2011.

[58] Ertürkmen, D., Dündar, C., Tokgöz, S., Karbon lifli polimer sargılı standart silindir beton numunelerin eksenel yük altındaki davranışlarının incelenmesi, Pamukkale Üniversitesi Mühendislik Bilimleri Dergisi, 23, 679-86, 2017.

[59] Gemi, L., Köroğlu, M.A., Çekme Bölgesi Lifli Beton Olan Cam Fiber Takviyeli Polimer (GFRP) ve Çelik Donatılı Etriyesiz Kirişlerin Eğilme Etkisi Altındaki Davranışı ve Hasar Analizi, S.Ü Müh Bilim ve Tekn Derg., 6, 654-67, 2018.

[60] Gemi, L., Köroğlu, M.A., Ashour, A., Experimental study on compressive behavior and failure analysis of composite concrete confined by glass/epoxy \pm 55 filament wound pipes, Composite Structures, 187, 157-68, 2018.

[61] Gemi, L., Madenci, E., Özkılıç, Y.O., An Investigation on Effect of Steel/Glass Fiber Bars in Concrete Beams, VI International Earthquake Symposium (IESKO 2019), 651-6, 2019.

[62] Gemi. L., Özkılıç, Y.O., Madenci, E., Investigation of Flexural Behavior of FRP Wrapped and Concrete Filled GFRP Box Profile Beams, VI International Earthquake Symposium (IESKO 2019), 605-10, 2019.

[63] Kang, T.H-K., Ary, M.I., Shear-strengthening of reinforced \& prestressed concrete beams using FRP: Part II-Experimental investigation. International Journal of Concrete Structures and Materials, 6, 49-57, 2012.

[64] Kuntal, V.S., Chellapandian, M., Prakash, S.S., Efficient near surface mounted CFRP shear strengthening of high strength prestressed concrete beams-An experimental study, Composite Structures, 180, 16-28, 2017.

[65] Özcan Z, Yöntem K. Betonarme Kirişlerin Kompozit Malzemeler ile Güçlendirilmesi, Deprem Sempozyumu, 1016-1022, 2005.

[66] Özkılıç, Y.O., Madenci, E., Gemi, L., Performance of Pultruded Glass Fiber Reinforced Polymer Composite Beams under Quasistatic Load, In The 5th International Conference on Engineering Science (ICES-2019), 2019.

[67] Pohl, G., Textiles., Polymers and composites for buildings, Elsevier, 2010. 
[68] Sayın, B., Manisalı, E., Lif Takviyeli Plastik Levhalar ile Güçlendirilmiş Betonarme Kirişlerde Arayüz Gerilmelerini Etkileyen Parametreler, Pamukkale Üniversitesi Mühendislik Bilimleri Dergisi, 16, 63-75, 2010.

[69] Soyaslan, A.E., Demiray, D., Tekstil Malzemelerinin İnşaat Mühendisliği Uygulamaları, Mehmet Akif Ersoy Üniversitesi Fen Bilimleri Enstitüsü Dergisi, 7, 2934, 2016.

[70] Aytaç, E., CFRP güçlendirme malzemesi ve güçlendirme teknikleri [Yüksek Lisans Tezi], Dokuz Eylül Üniversitesi, 2011.

[71] Gemi, L., Investigation of the effect of stacking sequence on low velocity impact response and damage formation in hybrid composite pipes under internal pressure, A comparative study, Composites Part B, Engineering, 153, 217-32, 2018.

[72] Morkavuk, S., Köklü, U., Bağcı, M., Gemi, L., Cryogenic machining of carbon fiber reinforced plastic (CFRP) composites and the effects of cryogenic treatment on tensile properties, A comparative study. Composites Part B, Engineering, 147, 1-11, 2018.

[73] Özütok, A., Madenci, E., Static analysis of laminated composite beams based on higher-order shear deformation theory by using mixed-type finite element method, International Journal of Mechanical Sciences, 130, 234-43, 2017.

[74] Mohandoss P., Pilla R.G., Sengupta A.K., "Effect of compressive strength of concrete on transmission length of pre-tensioned concrete systems" 23, 304-313, Structures, 2020 .

[75] Alberto T.Ramirez-Garciaa, Royce W.Floydb, W.Micah Halea, J.R.Martí-Vargasc, Effect of concrete compressive strength on transfer length, 5, 131-140, Structures,2016.

[76] R.W. Barnes J.W. GroveN.H. Burns, "Experimental Assessment of Factors Affecting Transfer Length” 100(6):740-748, ACI Structural Journal, 2003.

[77] Jin Kook Kim, Jun-Mo Yang, Hong Jae Yim, "Experimental Evaluation of Transfer Length in Pretensioned Concrete Beams Using 2,400-MPa Prestressed Strands", Journal of Structural Engineering 142(11):04016088, 2016.

[78] Ahmed Ghallab, A.W. Beeby, "Factors affecting the external prestressing stress in externally strengthened prestressed concrete beams", Cement and Concrete Composites 27(9-10):945-957,2005.

[79] Gemi, L., Aksoylu, C., Yazman, Ş., Özkılıç, Y.O., Arslan MH. Experimental investigation of shear capacity and damage analysis of thinned end prefabricated concrete purlins strengthened by CFRP composite, Composite Structures, 229, 111399, 2019.

[80] Eurocode2., Design of Concrete Structures-Part 1-1, General Rules and Rules for Buildings, 2005.

[81] du Béton FI., Practitioners guide to finite element modelling of reinforced concrete structures, State-of-Art Report, 2008.

[82] Desnerck, P., Lees, J.M., Morley, C.T., Strut-and-tie models for deteriorated reinforced concrete half-joints, Engineering Structures, 161, 41-54, 2018. 
[83] Fernández, R.M., Muttoni, A., On development of suitable stress fields for structural concrete, ACI, Structural Journal, 104, 495-502, 2007.

[84] Mitchell, D., Cook, W.D., Peng, T., Importance of reinforcement detailing. Special Publication, 273, 1-16, 2010.

[85] Schlaich, J., Schäfer, K., Jennewein, M., Toward a consistent design of structural concrete, PCI journal, 32, 74-150, 1987.

[86] Tjhin, T.N., Kuchma, D.A., Computer-based tools for design by strut-and-tie method: Advances and challenges, Structural Journal, 99, 586-94, 2002.

[87] Wang, Q., Guo, Z., Hoogenboom, P.C., Experimental investigation on the shear capacity of RC dapped end beams and design recommendations, Structural Engineering and Mechanics, 21, 221, 2005.

[88] Bergmeister, K., Breen, J., Jirsa, J., Kreger, M., Detailing in structural concrete. Center for Transportation Research, Report, 1993.

[89] MacGregor, J.G., Wight, J.K., Teng, S., Irawan, P., Reinforced concrete: mechanics and design Upper Saddle River, NJ, Prentice Hall, 1997.

[90] Özkılıç, Y.O., A new replaceable fuse for moment resisting frames, Replaceable bolted reduced beam section connections, Steel and Composite Structures, 35, 353-70, 2020.

[91] Dere, Y., Assessing a Retrofitting Method for Existing RC Buildings with Low Seismic Capacity in Turkey, Journal of Performance of Constructed Facilities, 31, 04016098, 2016.

[92] Hognestad, E., A Study of combined bending and axial load in reinforced concrete members [Doctoral Thesis], University of Illinois, Urbana, University of Illinois at Urbana Champaign, College of Engineering, 1951.

[93] Obaidat, Y.T., Heyden, S., Dahlblom, O., The effect of CFRP and CFRP/concrete interface models when modelling retrofitted RC beams with FEM, Composite Structures, 92, 1391-8, 2010.

[94] Behfarnia, K., Shirneshan, A., A numerical study on behavior of CFRP strengthened shear wall with opening. Comput Concrete, 19, 179-89, 2017.

[95] Sümer, Y., Aktaş, M., Defining parameters for concrete damage plasticity model, Challenge Journal of Structural Mechanics, 1, 149-55, 2015.

[96] Tahnat, YBA., Dwaikat, M.M., Samaaneh, M.A., Effect of using CFRP wraps on the strength and ductility behaviors of exterior reinforced concrete joint, Composite Structures, 201, 721-39, 2018.

[97] Zhang, D., Wang, Q., Dong, J., Simulation study on CFRP strengthened reinforced concrete beam under four-point bending, Computers and Concrete, 17, 407-21, 2016.

[98] Hashin, Z., Failure criteria for unidirectional fiber composites. Journal of applied mechanics, 47, 329-34, 1980. 
[99] Arduini, M., Nanni, A., Di Tommaso A., Focacci, F., Shear response of continuous RC beams strengthened with carbon FRP sheets, Non-Metallic (FRP) Reinforcement for Concrete Structures, Proceedings of the Third Symposium, 459-66, 1997.

[100] Kachlakev, D., McCurry, D., Behavior of full-scale reinforced concrete beams retrofitted for shear and flexural with FRP laminates, Composites Part B: Engineering, 31, 445-52, 2000.

[101] Lesani, M., Bahaari, M., Shokrieh, M., Numerical investigation of FRP-strengthened tubular T-joints under axial compressive loads, Composite Structures, 100, 71-8, 2013.

[102] Lesani, M., Bahaari, M., Shokrieh, M., Experimental investigation of FRPstrengthened tubular T-joints under axial compressive loads, Construction and building materials, 53, 243-52, 2014.

[103] Lesani, M., Bahaari, M., Shokrieh, M., FRP wrapping for the rehabilitation of Circular Hollow Section (CHS) tubular steel connections, Thin-Walled Structures, 90, 216-34, 2015.

[104] Rasheed, H.A., Larson, K.H., Amiri, S.N., Analytical solution of interface shear stresses in externally bonded FRP-strengthened concrete beams, Journal of Engineering Mechanics, 139, 18-28, 2011.

[105] Zhang, H., Huang, Y., Yang, Z., Xu, S., Chen, X., A discrete-continuum coupled finite element modelling approach for fibre reinforced concrete, Cement and Concrete Research, 106, 130-43, 2018.

[106] Qureshi, J., Lam, D., Behaviour of headed shear stud in composite beams with profiled metal decking, Advances in Structural Engineering, 15, 1547-58, 2012.

[107] Panigrahi, S.K., Deb, A., Bhattacharyya, S.K., Modes of Failure in Shear Deficient RC T-Beams Strengthened with FRP, Journal of Composites for Construction, 20:, $04015029,2016$.

[108] AASHTO., Guide Specifications for Horizontally Curved Steel Girder Highway Bridges, With Design Examples for I-girder and Box-girder Bridges, Washington, DC, American Association of State Highway and Transportation Officials, 2003.

[109] Müsevitoğlu, A., Arslan, M.H., Aksoylu, C., Özkış, A., Experimental and analytical investigation of chemical anchors's behaviour under axial tensile, Measurement. 158, $107689,2020$.

[110] Mansur, M., Tan, K-H., Wei, W., Effects of creating an opening in existing beams, Structural Journal, 96, 899-905, 1999.

[111] Abdalla H, Torkey A, Haggag H, Abu-Amira A. Design against cracking at openings in reinforced concrete beams strengthened with composite sheets, Composite Structures, 60, 197-204, 2003.

[112] Kalfat, R., Al-Mahaidi, R., Smith, S.T., Anchorage devices used to improve the performance of reinforced concrete beams retrofitted with FRP composites, State-ofthe-art review, Journal of Composites for Construction, 17, 14-33, 2013. 
[113] Grelle, S.V., Sneed, L.H., Review of anchorage systems for externally bonded FRP laminates, International Journal of Concrete Structures and Materials, 7, 17-33, 2013.

[114] Adhikary, B.B., Mutsuyoshi, H., Behavior of concrete beams strengthened in shear with carbon-fiber sheets, Journal of Composites for Construction, 8, 258-64, 2004.

[115] Siddika, A., Al Mamun, M.A., Alyousef, R., Amran, Y.M., Strengthening of reinforced concrete beams by using fiber-reinforced polymer composites, A review. Journal of Building Engineering, 100798, 2019.

[116] Madenci, E., Özkılıç, Y. O., \& Gemi, L. (2020). Buckling and free vibration analyses of pultruded GFRP laminated composites: Experimental, numerical and analytical investigations. Composite Structures, 254, 112806.

[117] Aksoylu, C., Yazman, Ş., Özkılıç, Y. O., Gemi, L., \& Arslan, M. H. (2020). Experimental analysis of reinforced concrete shear deficient beams with circular web openings strengthened by CFRP composite. Composite Structures, 249, 112561.

[118] Madenci E, Özkılıç YO, Gemi L. Theoretical Investigation on Static Analysis of Pultruded GFRP Composite Beams. Academic Platform Journal of Engineering and Science. 2020; 8(3): 483-489. 